\title{
Use of in vitro bone models to screen for altered bone metabolism, osteopathies, and fracture healing: challenges of complex models
}

\author{
Sabrina Ehnert ${ }^{1}$ D $\cdot$ Helen Rinderknecht $^{1} \cdot$ Romina H. Aspera-Werz $^{1} \cdot$ Victor Häussling $^{1} \cdot$ Andreas K. Nussler $^{1}$ D
}

Received: 6 May 2020 / Accepted: 3 September 2020 / Published online: 10 September 2020

(c) The Author(s) 2020

\begin{abstract}
Approx. every third hospitalized patient in Europe suffers from musculoskeletal injuries or diseases. Up to $20 \%$ of these patients need costly surgical revisions after delayed or impaired fracture healing. Reasons for this are the severity of the trauma, individual factors, e.g, the patients' age, individual lifestyle, chronic diseases, medication, and, over 70 diseases that negatively affect the bone quality. To investigate the various disease constellations and/or develop new treatment strategies, many in vivo, ex vivo, and in vitro models can be applied. Analyzing these various models more closely, it is obvious that many of them have limits and/or restrictions. Undoubtedly, in vivo models most completely represent the biological situation. Besides possible species-specific differences, ethical concerns may question the use of in vivo models especially for large screening approaches. Challenging whether ex vivo or in vitro bone models can be used as an adequate replacement for such screenings, we here summarize the advantages and challenges of frequently used ex vivo and in vitro bone models to study disturbed bone metabolism and fracture healing. Using own examples, we discuss the common challenge of cell-specific normalization of data obtained from more complex in vitro models as one example of the analytical limits which lower the full potential of these complex model systems.
\end{abstract}

Keywords Ex vivo bone cultures $\cdot$ Osteoblast/osteocyte $\cdot$ Osteoclast $\cdot$ Endothelial cells $\cdot$ Co-culture $\cdot 2 \mathrm{D} / 3 \mathrm{D}$

\section{Introduction}

\section{Bones of the skeleton are more than the supporting framework for the human body}

Based on recent statistical investigations, approx. every third hospitalized patient in Europe suffers from musculoskeletal injuries or diseases. Their treatment makes up to $15 \%$ of all therapeutic costs (Eurostat), of which most costs being caused by surgical revisions after delayed or impaired fracture healing. A large British study with almost 3000 patients showed delayed or impaired fracture healing in $20 \%$ of these patients (Hernandez et al. 2012). Besides the type and severity of the trauma, individual factors including the patients' age and individual lifestyle (e.g., reduced physical activity,

Sabrina Ehnert

sabrina.ehnert@med.uni-tuebingen.des;

abrina.ehnert@gmail.com

1 Siegfried Weller Research Institute at the BG Trauma Center Tübingen, Department of Trauma and Reconstructive Surgery, University of Tübingen, Tübingen, Germany imbalanced diet, alcohol, or cigarette consumption), as well as emerging chronic diseases and their medication strongly affected fracture risk and fracture healing (Hernandez et al. 2012; Ihle et al. 2017; Schlundt et al. 2018; Sheu and Diamond 2016). Indeed, today, over 70 diseases and health conditions are known that negatively affect bone quality and, thus, increase fracture risk. The increasing prevalence and incidence of such disease-associated changes in bone quality favored the establishment of the terms systemic bone disease and secondary osteoporosis. Facing constantly increasing life expectancy and ageing society, systemic bone diseases and secondary osteoporosis gain more and more relevance. For example, in a representative German level 1 trauma center, $80.5 \%$ of all patients suffer from one or more chronic diseases requiring medication $(\varnothing 4.3$ drugs per patient): approx. 13\% are diabetics (Pscherer et al. 2016b, 2015), 22\% are at risk for malnutrition (Ihle et al. 2017), $15 \%$ drink alcohol on a daily base, and $42 \%$ are smokers (Ehnert et al. 2019a). These patients are above-average in developing post-surgical complications, e.g., delayed wound or fracture healing, which, in turn, results in significantly 
prolonged hospital stays (Wintermeyer et al. 2018), and often aggravates the underlying disease.

Diabetes mellitus (DM) may serve as good example, representing the metabolic disease with the highest prevalence and incidence in developed countries (Hopps and Caimi 2011). Due to the classical DM-dependent complications, e.g., hypoglycemic or hyperglycemic episodes, impaired vision, or polyneuropathies diabetics have a higher frequency of falls. Due to structural changes of bones [type $1 \mathrm{DM}$ : osteopenia and osteoporosis/type $2 \mathrm{DM}$ : increased bone mineral density (Blakytny et al. 2011; Hofbauer et al. 2016; La Fontaine et al. 2011)], fracture rate is significantly higher in diabetics than in metabolically healthy controls (Hamann et al. 2012; Hofbauer et al. 2007), and seems at least partly to be influenced by the medication obtained (Hidayat et al. 2019; Kalaitzoglou et al. 2019; Kheniser et al. 2018; Pscherer et al. 2016a). For example, diabetics treated with sulfonylurea are commonly associated with a higher risk of falls and fractures (Adil et al. 2017; Lapane et al. 2015; Rajpathak et al. 2015). Similarly, an increased fracture risk has been reported in diabetics receiving glitazones and sodium-glucose transport protein 2 inhibitors for blood glucose control (Lim et al. 2017; Mori et al. 2017; Soroceanu et al. 2004; Watts et al. 2016). The first-line medication for type 2 diabetes is Metformin, which is not associated with an increased fracture risk (Hegazy 2015). Interestingly, studies suggest that incretin-based drugs, e.g., glucagon-like peptide 1 receptor agonists and Dipeptidyl-peptidase 4 inhibitors, can even favor bone health (Nuche-Berenguer et al. 2009; Yang et al. 2017). These data are retrieved from databanks reporting the incidence of fractures. Although this can give valuable advice when choosing a treatment, one cannot conclude on the underlying mechanisms. For obtaining such information, advanced model systems are required.

The example on DM shows how a disease can disturb the balanced interplay between the bone resident cells, controlling bone formation and resorption, either directly or indirectly by its medication. The resulting changes in bone quality may increase the risk for fractures. In case of a fracture, possible disease-related alterations in the local blood vessels (micro- and macro-angiopathies) and inflammation in the surrounding soft tissue, often negatively affect the fracture healing (El-Ganainy and Elgeidi 2010; Kline et al. 2009; Mazziotti et al. 2011; Mehta et al. 2010; Retzepi and Donos 2010; Robinson et al. 2009; Wukich et al. 2011). Therefore, models investigating fracture healing should also address points, e.g., inflammation and vascularization.

There is first evidence that the disease-dependent alterations in the bone also affect other organs within the human body. Researchers in Colorado (USA) proved that production of insulin by $\beta$-cells, and thus regulation of blood sugar levels, is tightly controlled by osteocalcin produced by bone forming osteoblasts (Hwang et al. 2011; Kidder et al. 2009; Villafan-Bernal et al. 2011). Hyperglycemic episodes and compensatory formation of insulin suppress maturation of osteoblasts, by stimulating the production, release, and activation of TGF- $\beta$ (transforming growth factor beta) by osteoblasts, osteoclasts (Ehnert et al. 2010; Ehnert et al. 2017; Freude et al. 2012), and immune cells. Serum levels of active TGF- $\beta$ are chronically elevated in diabetics, which may act immune-modulatory and profibrotic throughout the entire body (Ehnert et al. 2015; Pscherer et al. 2013). Normally produced to fight excessive inflammation, chronically elevated TGF- $\beta$ levels in diabetics may suppress acute immune responses and thus favor infections in these patients. Furthermore, TGF- $\beta$ as a key driver in scar formation is known to favor fibrosis and cirrhosis in various tissues, including kidney, liver, heart, and lung (Fabregat and Caballero-Diaz 2018; Lichtman et al. 2016; Meng et al. 2016; Yue et al. 2017). Thus, DM represents a prime example for the underestimated role of the bones in the human body.

\section{Cellular interactions in bones}

Facing new regulations on the re-evaluation and licensing of drugs and medical devices, it should be mandatory to examine the effect of drugs, especially that for sustainable medication, on the bone health. In the human body, bones of the skeleton constantly adapt to the stress exposed. New bone structures are formed by cells of the osteogenic lineage, e.g., mesenchymal stem cells (MSCs), osteoblasts, and osteocytes. Inferior or damaged bone matrix is resorbed by osteoclasts, derived from the hematopoietic lineage. In the bone marrow, new blood cells are produced, which provide bone cells with required oxygen and nutrients via a system of blood vessels (Buckwalter et al. 1996; Florencio-Silva et al. 2015). Therefore, healthy bone function requires an orchestrated interplay between vessel forming endothelial cells, blood cells, bone forming, and resorbing cells, that are often mediated via paracrine and systemic mediators. Yet, little is known about the role of the bone marrow-resident adipocytes (Horowitz et al. 2017). In case of a fracture, additional factors gain importance, e.g., the invading immune cells which represent main drivers for successful bone healing (Kolar et al. 2010; Ma et al. 2019; Pfeiffenberger et al. 2019). Therefore, depending on the intended research interest, in vitro or ex vivo model systems have to display the complex interactions of many different cell types (Fig. 1). 


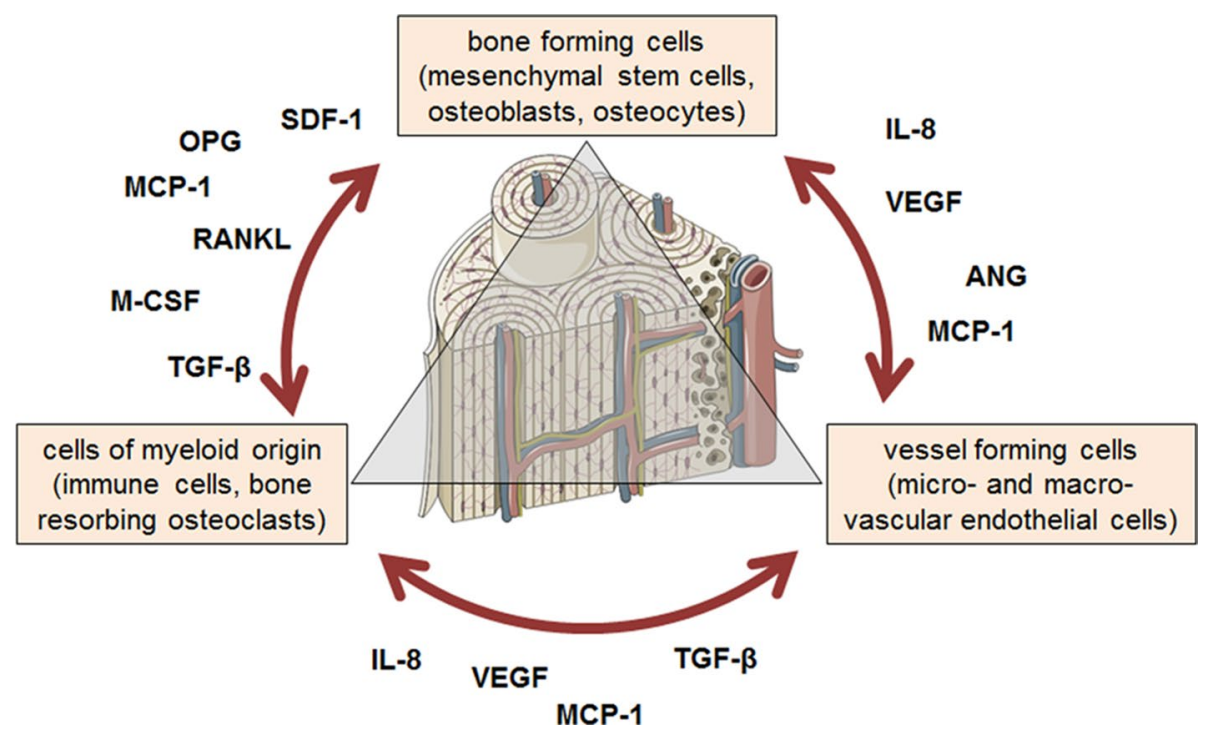

Fig. 1 Overview of the different cell types within the bone. Cells resident in the bone communicate with each other by direct cell-cell and cell-matrix interactions, as well as via secreted factors. Representatives of these factors are given in the figure: ANG (angiogenin), IL-8 (interleukin 8), VEGF (vascular endothelial growth factor), MCP-1 (monocyte chemoattractant protein), OPG (osteoprotegerin), RANKL (receptor activator for nuclear factor kappa B ligand), TGF- $\beta$ (transforming growth factor beta), and SDF-1 (stromal cell-derived factor-1) Bone sketch was obtained from https://smart.servier.com/

high degree of reproducibility. Due to the larger size of the bones for example in pigs, dogs, or sheep, the fixation of the fractured bones is quite representable to the human situation. Therefore, larger animals are preferably used to test orthopedic implants or biomaterials (Haffner-Luntzer et al. 2019). Additionally, in some of these models, primary (postmenopausal) osteoporosis can be induced by ovariectomy in female animals (Haffner-Luntzer et al. 2019). This brief overview shows the advantages and great variety of existing in vivo models when it comes to investigating bone metabolism, systemic bone diseases, or fracture healing. However, some limitations remain to be addressed:

- There exist partly huge species-dependent differences in bone metabolism (Aerssens et al. 1998);

- The use of inbred rodent strains cannot display the great inter-individual differences observed in humans;

- Due to strictly controlled housing conditions, animals are not exposed to the same environmental influences as patients, especially in case of a disease;

- Based on the altered posture (tetrapod motion vs upright walk), mechanical strain in bones often differs between animals and humans.

- A considerable amount of animals is needed to obtain representative results.

Taking up the example of DM again, there exist a great variety of animal models, in which DM is induced either genetically (for example Lep ${ }^{\mathrm{ob} / \mathrm{ob}}$, LepR ${ }^{\mathrm{db} / \mathrm{db}}$, TallyHo/JngJ, 
KK, NZO or MKR mice and ZDF, OLETF, or GK rats) or by a specific diet (for example by high caloric and fatty diet) (King 2012; Rees and Alcolado 2005). Focusing on rodent models for type 2 diabetes, bone mineral density often suggests the development of osteopenia and osteoporosis. This is contrary to the human situation, where type 2 diabetics often leads to higher bone mineral density than age- and gender-adjusted controls (Kawashima et al. 2009; RendinaRuedy et al. 2016; Rosen and Bouxsein 2006; Won et al. 2011).

Besides associated ethical concerns, this example shows that animal models are only of limited use to investigate metabolic bone diseases or the influence of drugs on the bone. This example underlines the absolute need for models adequately representing the human bone disease.

\section{Ex vivo bone cultures}

Culture models closest to the in vivo situation are the socalled ex vivo organ cultures. Depending on the research interest, different ex vivo bone cultures exist (Fig. 2).

Stem cell behavior during linear bone growth and hypertrophic ossification is best observed in the so-called long bone or limb organ cultures. In the literature, different long bone organ cultures are described (Abubakar et al. 2019; Houston et al. 2016; Muzic et al. 2013; Paradis et al. 2019; Parivar et al. 2006; Proffit and Ackerman 1964; Smith et al. 2013, 2015; Uribe and Rosello-Diez 2019). Already in the 1960s, ex vivo long bone cultures have been described (Proffit and Ackerman 1964): proximal phalanges, metacarpal, and metatarsal bones were dissected from the paws of young rats and kept several days in culture, during which the bones grew and mineralized (Abubakar et al. 2019; Proffit and Ackerman 1964). This method was also described for long bones of mice (Houston et al. 2016; Kunimoto et al. 2016; Okubo et al. 2015, 2013; Uribe and Rosello-Diez 2019) or chicken (Smith et al. 2015). Based on the study from Abubakar et al, approx. $75 \%$ of ex vivo bone growth studies are performed using ex vivo long bone cultures (Abubakar et al. 2016). By culturing an explanted bone, the complete cellular composition of the intact organ is provided, representing closely the in vivo situation. This is a great advantage, when bone growth or, to a certain degree, bone metabolism is investigated. Preserving the surrounding soft tissue, during the so-called limb bud cultures promised even better representation of the in vivo situation (Muzic et al. 2013; Paradis et al. 2019; Parivar et al. 2006; Smith et al. 2013). As a fracture model, a limiting factor will be the lack of the vascular system, which is required for the formation of the fracture hematoma (Kolar et al. 2010).

Murine or rat femur head and calvarial cultures (Batushansky et al. 2019; Garrett 2003; Madsen et al. 2011; Mohammad et al. 2008; Sathi et al. 2015) comprise approx. $16 \%$ of ex vivo bone growth studies (Abubakar et al. 2016). However, these cultures can also be used for investigating bone and cartilage metabolism or bone defect healing. When cocultured with other cells, e.g., cancer cells or immune cells, even for investigating bone metastases (Choudhary et al. 2018; Curtin et al. 2012; Marino et al. 2019; Salamanna et al. 2016; Salih 2019) or inflammatory bone diseases (Sloan et al. 2013).

\begin{tabular}{|c|c|c|c|c|}
\hline $\begin{array}{l}\text { long bone / limb } \\
\text { organ culture }\end{array}$ & $\begin{array}{l}\text { femur head } \\
\text { culture }\end{array}$ & $\begin{array}{l}\text { calvarial } \\
\text { culture }\end{array}$ & $\begin{array}{l}\text { mandible / molar } \\
\text { slice cultures }\end{array}$ & $\begin{array}{l}\text { trabecular core } \\
\text { culture }\end{array}$ \\
\hline day 1 & & & & \\
\hline $\begin{array}{c}\text { day } 14 \\
\text { mineralizing zone }\end{array}$ & & & & \\
\hline $\begin{array}{l}\text { proliferating hypertrophic } \\
\text { zone }\end{array}$ & & & $\forall \bullet$ & $\Leftrightarrow$ \\
\hline $\begin{array}{l}\text { linear bone growth, } \\
\text { stem cell behavior }\end{array}$ & $\begin{array}{l}\text { bone metabolism, } \\
\text { cartilage metabolism }\end{array}$ & $\begin{array}{l}\text { bone metabolism, } \\
\text { defect/bone healing }\end{array}$ & $\begin{array}{l}\text { stem cell behavior, } \\
\text { bone repair model }\end{array}$ & $\begin{array}{l}\text { bone metabolism, } \\
\text { defect/bone healing }\end{array}$ \\
\hline \multicolumn{3}{|c|}{ mice } & & larger animals, \\
\hline \multicolumn{4}{|c|}{ rats } & e.g. sheep, pigs, cows, \\
\hline chicken & & & \multicolumn{2}{|c|}{$\operatorname{man}$} \\
\hline
\end{tabular}

Fig. 2 Overview of different available ex vivo bone models 
It has been critically discussed whether ex vivo bone cultures requiring specific and/or intact bones can significantly reduce the amount of experimental animals used, when per animal often only two conditions can be tested (Barrach and Neubert 1980; Lessmollmann et al. 1976). Better efficiency in reducing the number of experimental animals is given when the explanted bones are sliced, e.g., in the model described by Srinivasaiah et al. where femurs of young rats are sliced into discs with a thickness of each $300 \mu \mathrm{m}$ (Srinivasaiah et al. 2019). Similar holds for mandible slice cultures. Unfortunately, destroying the intact explanted organ may affect the cellular composition within the model, as certain cell types can only be found in a specific niche within the organ (Birbrair and Frenette 2016; Morrison and Scadden 2014; Pinho and Frenette 2019). This might be one reason why slice cultures make up the least proportion of ex vivo bone growth studies (Abubakar et al. 2016). So far, mandible or molar slice cultures are preferably used to investigate stem cell behavior and bone repair (Alfaqeeh and Tucker 2013; Colombo et al. 2015; Marino et al. 2016; Smith et al. 2010). The main advantage of mandibular slice cultures is that they can be transferred into the human situation. To do so, immature molar slices from young adults were cultured for several days, to investigate biocompatibility of filling materials and to investigate odontoblast response to damage, eliminating possible species-dependent differences (Melin et al. 2000; Tecles et al. 2008).

Similarly, trabecular core cultures utilize bones of larger animals and even humans (Davies et al. 2006; Endres et al. 2009; Kluter et al. 2020; Knothe Tate and Knothe 2000; Rawlinson et al. 1991; Simpson et al. 2009; Stoddart et al. 2006; Templeton et al. 2015; Vivanco et al. 2013). The larger trabecular core cultures are used to investigate bone metabolism, especially in response to mechanical load (David et al. 2008; Davies et al. 2006; Knothe Tate and Knothe 2000), but the model can also be used to investigate biocompatibility of materials during defect healing (Kluter et al. 2020), or as model to investigate cancer-dependent effects on bone (Salih 2019). In contrast to slice cultures, which are comprised of a trabecular and cortical bone compartment, trabecular core cultures mainly consist of trabecular bone. Therefore, trabecular core cultures represent a great model to investigate alterations in bone metabolism and biocompatibility of materials. The possibility to generate these ex vivo cultures from human bone slices or biopsies further allows investigation of molecular mechanisms in metabolic bone diseases, when the bone samples are obtained from patients with the underlying disease (Bellido and Delgado-Calle 2020; Owen and Reilly 2018). When the models should be used for screening approaches, one has to keep in mind the metabolism of the different drugs within the body, e.g., first path effects and metabolism in the liver. When screening for effects of established drugs on bone metabolism, this may not be a problem, as the known metabolites can be tested. It becomes challenging, when novel substances shall be screened-in this case, only direct effects of the drugs on the bone tissue can be observed, e.g., seen with implant coatings. Furthermore, the availability of the required native human or large animal material is still limited, such that these models cannot be easily used for large-scale drug/substance screenings. This raises the need for a permanently available and up-scalable in vitro model, which represents metabolism and vasculature of human bone.

\section{In vitro models}

In the past years, several attempts have been explored to establish model systems that represent bone metabolism and vasculature. It is self-explanatory that these processes cannot be displayed in conventional 2D mono-cultures. In the conventional 2D cultures on cell culture plastic, the organic (mostly collagen) and inorganic (mostly hydroxyapatite) matrix characteristics for bone are missing. However, this bone matrix essentially functions as regulators for bone cell function and differentiation (Florencio-Silva et al. 2015; Green et al. 1995). Furthermore, in most cases, a co-culture of 2 or sometimes 3 cell times was described, which cannot adequately represent the in vivo situation. Being able to mix only a limited amount of cell types with each other, the purpose of the in vitro models has to be clearly defined. When investigating the biocompatibility of implant materials or bone metabolism, bone forming osteogenic cells and bone resorbing osteoclastic cells are essential. It has been reported that vessel forming endothelial cells or even hematopoietic cells affect bone metabolism (Fuchs et al. 2009, 2007); therefore, including these cell types in the co-culture shall be considered. In case of investigating effects during fracture healing, not only addition of hematopoietic and endothelial cells but all sorts of immune cells should be considered, as they comprise the fracture hematoma in vivo (Kolar et al. 2010). Hematopoietic cells and immune cells are also crucial for testing biocompatibility of materials, but in this case, the so-called hemocompatibility and inflammatory response are investigated separately.

Previous attempts to establish co-cultures based on primary human osteoclasts, osteoblasts, and/or osteocytes to resemble bone metabolism proved to be strongly donordependent and time-consuming:

- To obtain a number of osteoblasts and/or osteocytes sufficient for experiments, the cells have to be cultured for several weeks up to months;

- The use of osteoprogenitor cells, e.g., MSCs derived from bone marrow or fat tissue may speed up the expansion time, but might elongate the period of differentiation (Ehnert et al. 2011; Zachos et al. 2014); 
- By that time, the donors will no longer be available for a blood donation to generate osteoclasts; therefore, a compatible donor for the isolation of monocytes has to be found;

- Meeting these requirements, the co-culture itself lasts up to 6 weeks depending on the protocol used (Forte et al. 2016; Greiner et al. 2009; Heinemann et al. 2011, 2013; Jablonski et al. 2016; Papadimitropoulos et al. 2011; Penolazzi et al. 2016; Tortelli et al. 2009; Wu et al. 2015; Zehnder et al. 2017);

To quickly obtain larger amounts of cells, a few models utilize human cell lines for their co-cultures (Jablonski et al. 2016; Wu et al. 2015). This has the advantage that large amounts of cells can be obtained in a short time to provide sufficient amount of model material for larger screening approaches. However, one cannot neglect that the choice of the cell line has to be carefully done to represent best the primary counterpart and even then the use of cell lines cannot represent the inter-individual differences characteristic for humans.

The co-culture models not only differ in the type of cells used. There are also essential differences in the individual setup of the co-cultures (Fig. 3). Again considering only co-cultures of bone forming and resorbing cells:

- Not all co-cultures allow direct cell-cell interactions (Forte et al. 2016);

- Even less provide cell-matrix interactions (Forte et al. 2016; Heinemann et al. 2011, 2013; Tortelli et al. 2009; Wu et al. 2015);
- Only a few models respect the natural 3D organization of cells (Heinemann et al. 2013; Papadimitropoulos et al. 2011; Penolazzi et al. 2016; Tortelli et al. 2009);

- And only one model considers mechanical stimulation of bone cells (Penolazzi et al. 2016).

Recently, there is growing evidence that osteogenic and osteoclastic cells are not only influenced by the surrounding matrix (Florencio-Silva et al. 2015; Green et al. 1995) and mechanical stimuli (Frost 1994), but also strongly by bone marrow resident adipocytes (Horowitz et al. 2017) or endothelial cells of blood vessels (Kirkpatrick et al. 2011). However, it is not yet known how changes in bone metabolism affect vascularization or vice versa how an altered vasculature affects bone metabolism. So far, most co-culture models focused on the influence of osteogenic cells and endothelial cells in direct and indirect co-cultures (Fuchs et al. 2007; Ghanaati et al. 2011; Hofmann et al. 2008; Li et al. 2014; Ma et al. 2020; Shi et al. 2016; Sun et al. 2016), not considering, that the interplay of the presence of osteoclastic cells may alter the function of the osteogenic cells or vice versa (Zachos et al. 2014). Even more complex is the situation, when investigating fracture healing. There, the fracture hematoma consisting of hematopoietic cells and different immune cells is thought to be the key driver for fracture healing (Kolar et al. 2010). Pfeiffenberger et al. have described an equine in vitro model, addressing this complex situation, using coagulated blood as 3D carrier for mesenchymal stem cells (Pfeiffenberger et al. 2019).

Furthermore, the bone is not an isolated organ. Many drugs get after first path effect activated and metabolized in the liver. Therefore, the discussion arose whether bone

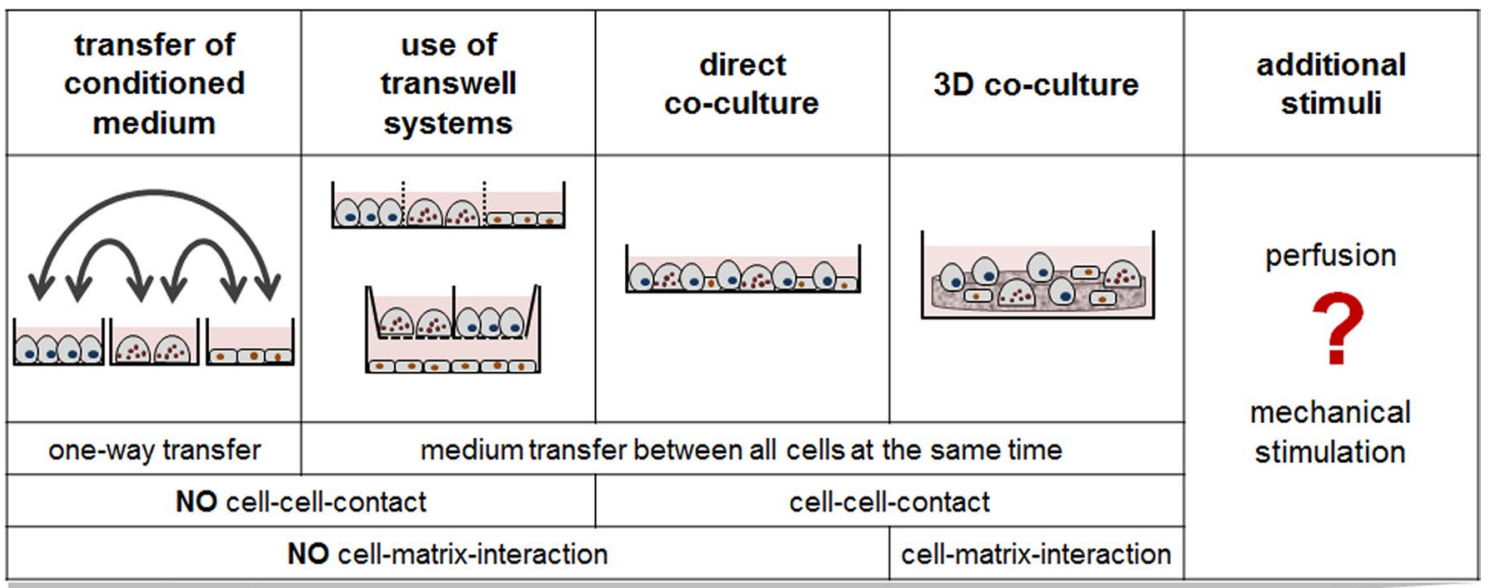

number of established methods

Fig. 3 Advantages and disadvantages of the different available in vitro bone models. With increasing complexity of the model system, fewer methods are available for analyses 
cultures shall be included in the so-called organ on a chip approaches. A simpler way would be to test the effect of not only native but also activated or metabolized substances on the bone cultures. As elaborated above this may not be a problem when screening for effects of established drugs on bone metabolism but becomes challenging, when novel substances shall be screened. However, this approach is only feasible when a suitable human ex vivo or in vitro model is available in large quantities.

\section{Challenges of the in vitro models}

Increasing the number of cell types in a co-culture while addressing the requirements on $3 \mathrm{D}$ conformation, matrix composition, and mechanical stimuli, e.g., mechanical load or perfusion, significantly increases the complexity of the culture model, which, in turn, limits the availability of methods for analysis (James Kirkpatrick et al. 2007). For overview see Fig. 4.

\section{Medium composition}

All cell types have individual requirements on the medium composition. Therefore, considering different cell types for a co-culture may require modulation of the medium composition. For example, osteogenic differentiation medium frequently contains dexamethasone, which is a well-known immune-suppressant. By altering the immune response of mononuclear cells, the glucocorticoid may interfere with osteoclast formation in co-cultures addressing bone metabolism (Kim et al. 2006; Warabi et al. 2001). Dexamethasone in the differentiation medium may be replaced by cholecalciferol (vitamin $\mathrm{D}_{3}$ ), which acts via the vitamin $\mathrm{D}$ receptor both on osteogenic and osteoclastic cells (Ehnert et al. 2011). And yet mononuclear cells as precursors for osteoclasts need to be activated to attach to the cell culture plastic and differentiate into osteoclasts. Human myeloid cell lines, e.g., THP-1 or HL-60, normally get activated upon exposure

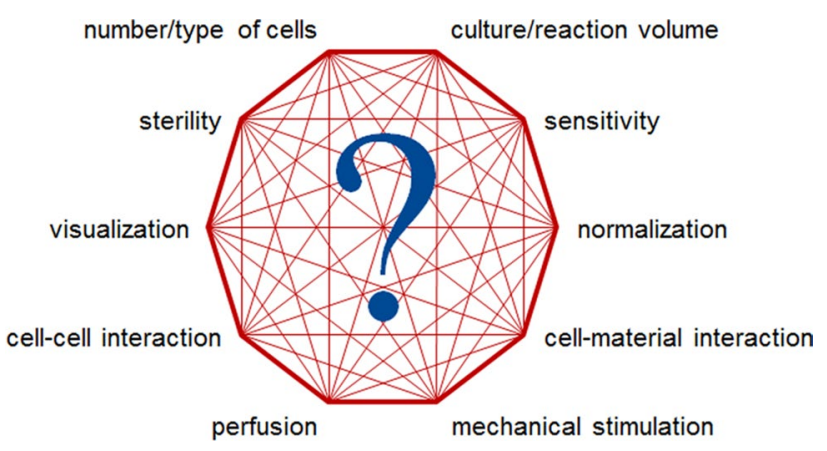

Fig. 4 Schematic overview of the factors influencing each other in complex model systems to PMA (phorbol 12-myristate 13-acetate) (Daigneault et al. 2010; Padilla et al. 2000), which, in turn, may affect function of other cells in the co-culture. In this case, sequential seeding of the cells may be inevitable to prevent an unwanted exposure to PMA. Addition of PMA is not required when using murine macrophage cell lines, e.g., RAW 264.7 or $\mathrm{J} 774$, which are adherent cells by nature. Osteoclast differentiation is normally induced by the addition of macrophage colony-stimulating factor (M-CSF) and receptor activator of NF- $\kappa B$ ligand (RANKL) to the medium. These two factors are produced by many osteogenic cells, such that these supplements may be reduced or even removed from the coculture medium. When additionally, vascularization shall be addressed, endothelial cells have to be included in the co-culture model. Endothelial cells normally grow in more complex media than osteogenic or osteoclastic cells. The various growth factors included in their medium, e.g., vascular endothelial growth factor 165, epidermal growth factor, basic fibroblast growth factor, or insulin-like growth factor, may affect the other cells in the co-culture, possibly aggravating the inclusion of these cells in a co-culture.

\section{Choice of cell types and cell-cell ratios}

Even simpler seem the questions for the adequate cell types and cell numbers for a co-culture. Resuming the example of M-CSF and RANKL, which should be produced by osteogenic cells-however, when comparing the three most commonly used osteogenic cell lines MG-63, Cal-72, and SaOS2 , expression of $M-C S F$ seems to increase with increasing degree of osteogenic differentiation of these cells (Rochet et al. 2003). However, depending on the subset of cells in culture, $M-C S F$ expression may be even absent (Trojani et al. 2005). We have observed similar effects with $R A N K L$ expression: while SaOS-2 cells express $R A N K L$ in levels comparable to human osteoblasts, Cal-72 cells barely express $R A N K L$. These cell lines not only differ in their expression profile, but also in proliferation and osteogenic differentiation (Lauvrak et al. 2013) — therefore, when considering the highly proliferative MG-63 cells for co-culture, less cells might be needed than when using Cal-72 cells or $\mathrm{SaOS}-2$ cells. Even more difficult is finding the right density of myeloid cells applied to the co-culture. During seeding, the density of the myeloid cells should be high to allow fusion of the cells to pre-osteoclasts (Jansen et al. 2012). However, to resemble the cell-cell ratio observed in bone, during maturation, the cell ratio of osteoclasts and osteogenic cells has to shift strongly towards the osteoblasts and osteocytes, which make up to $95 \%$ of the cells in the bone (Florencio-Silva et al. 2015). Similar holds for the endothelial cells. These cells normally require a certain cell density on soft surfaces to migrate towards each other, align, and form tubes (Arnaoutova and Kleinman 2010). So far, it is not 
known how these cells may act in a direct co-culture, when the matrix gets mineralized by osteoblasts or even degraded by osteoclasts.

\section{Characteristics of the carrier material}

Taking into consideration that the surrounding matrix is not only essential for tube formation of endothelial cells but also regulates bone metabolism, the right choice of material seems to be fundamental. While endothelial tube formation assay is mainly done on soft hydrogels in 2D culture (Arnaoutova and Kleinman 2010), caving in soft hydrogels may prevent the fusion of monocytic cells early in osteoclastogenesis. Furthermore, there is evidence that 3D arrangement of cells on stiff and porous carriers favors osteogenic maturation of cells (Griffith and Swartz 2006). For bone tissue engineering, a large number of different hydroxyapatite-containing scaffolds exist (Ayobian-Markazi et al. 2012; George et al. 2006; Jain et al. 2015; Mayr-Wohlfart et al. 2001), which favor cell attachment, proliferation, and maturation of osteogenic cells (Jain et al. 2015; Thein-Han and Misra 2009). Therefore, 3D cultures seem to be more beneficial for the differentiation when compared to $2 \mathrm{D}$ cultures (Bulnheim et al. 2014). Therefore, when a co-culture of osteogenic and osteoclastic cells with endothelial cells is aspired, an indirect co-culture approach, i.e., by separation with permeable culture inserts, could be advantageous as the soft hydrogel required by the endothelial cells can be easily combined with a stiffer and porous $3 \mathrm{D}$ carrier required by the bone cells. However, 3D cultures also raise new challenges, i.e., proper adjustment of the physical characteristics of the 3D matrix to the human physiology, uniform cell seeding on scaffolds, and adequate supply with nutrients (Henkel et al. 2013), factors associated with each other. Pore size, porosity, water uptake rate, and stiffness are essential physical characteristics of scaffolds (Haussling et al. 2019; Weng et al. 2020; Zhu et al. 2018). Pore size and porosity affect both cell attachment and cell infiltration into the scaffold (Murphy and O'Brien 2010). Furthermore, these factors and the water uptake rate are directly associated with nutrient and waste diffusion, a factor that may be actively influenced by applying medium flow to the cultures (Murphy and O'Brien 2010). There are studies, showing that carriers with stiffness over $60 \mathrm{kPa}$ favor osteogenic differentiation of MSCs (Engler et al. 2006; Sun et al. 2018). Lowering the stiffness of scaffolds may induce expression of stem cell markers, e.g., Sox2, in MSCs, which proved to inhibit osteogenic differentiation (Ding et al. 2012; Marcellini et al. 2012; Park et al. 2012; Seo et al. 2013) in favor for adipogenic differentiation (Zhao et al. 2014). However, the chosen scaffolds should also not be too stiff to pass on mechanical stimuli to cells (Dawson and Oreffo 2008).

\section{Reaction volume of the model system}

Besides the effects, the physical characteristics of the carrier material might have on the co-culture; the ratio of culture medium to cell number has to be considered, too. In a static $3 \mathrm{D}$ co-culture to completely cover cells on porous scaffolds with medium, the volume is likely to be increased. In this case, the increase in medium volume may be at least partly be compensated by the increase in surface area available for the cells to attach and grow (Hadida and Marchat 2020; Zhang et al. 2018). However, applying mechanical forces or perfusion to a model system would increase the required culture/reaction volume even more without any compensation in cell numbers and may increase the risk for contaminations due to the increased number of structural junctions (Hadida and Marchat 2020). An increase in culture/reaction volume would dilute factors secreted by cells in the culture medium and thus effectively lowers the sensitivity of established analytical methods. However, the use of scaffolds bares also other challenges:

- The scaffold limits microscopic analyses-the use of fluorophores may circumvent some of these limitations (Tendulkar et al. 2016); however, penetration depth and possible autofluorescence of the material remain limiting factors.

- Assay substrates and reaction products require time for perfusion.

- Assay substrates or reaction products may react with the scaffold material.

- The scaffold material or particles released from the carrier into the reaction solution may disturb photometric measurements.

- Cells may not be efficiently released from the scaffolds, which may disturb or even impede preparation of RNA or protein lysates for analyses.

\section{Normalization of functional assays in complex in vitro models}

Undoubtedly, co-cultures represent a great chance for research and screening purposes; however, the described mainly technical limitations suppress their full potential. While some limitations can be addressed by a deliberate choice of cells and materials, others are not that easy to address. Often forgotten is the cell-specific normalized of functional measurements in co-cultures, an important issue that will be further explored in the following section. For overview, see Table 1. 
Archives of Toxicology (2020) 94:3937-3958

3945

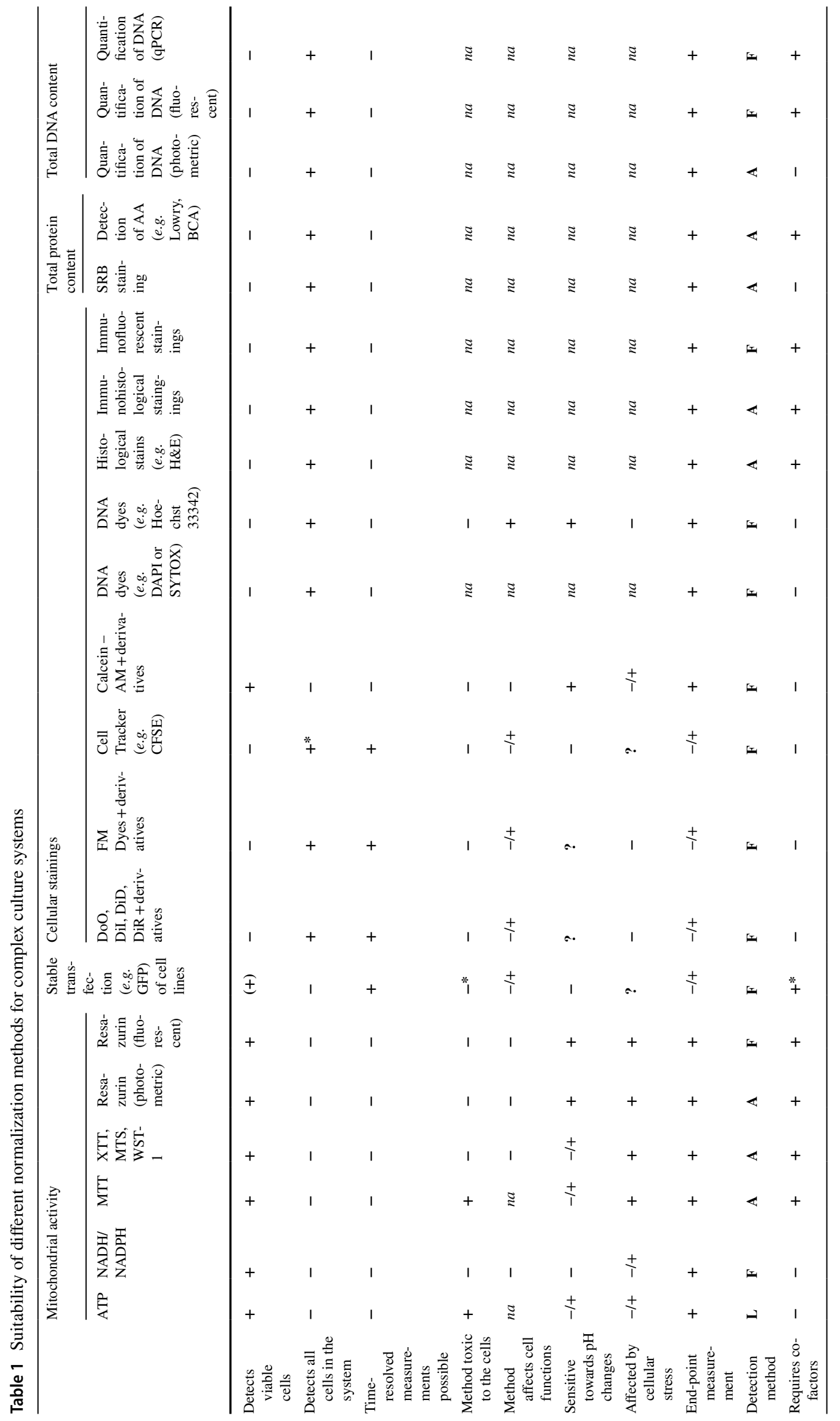

Springer 


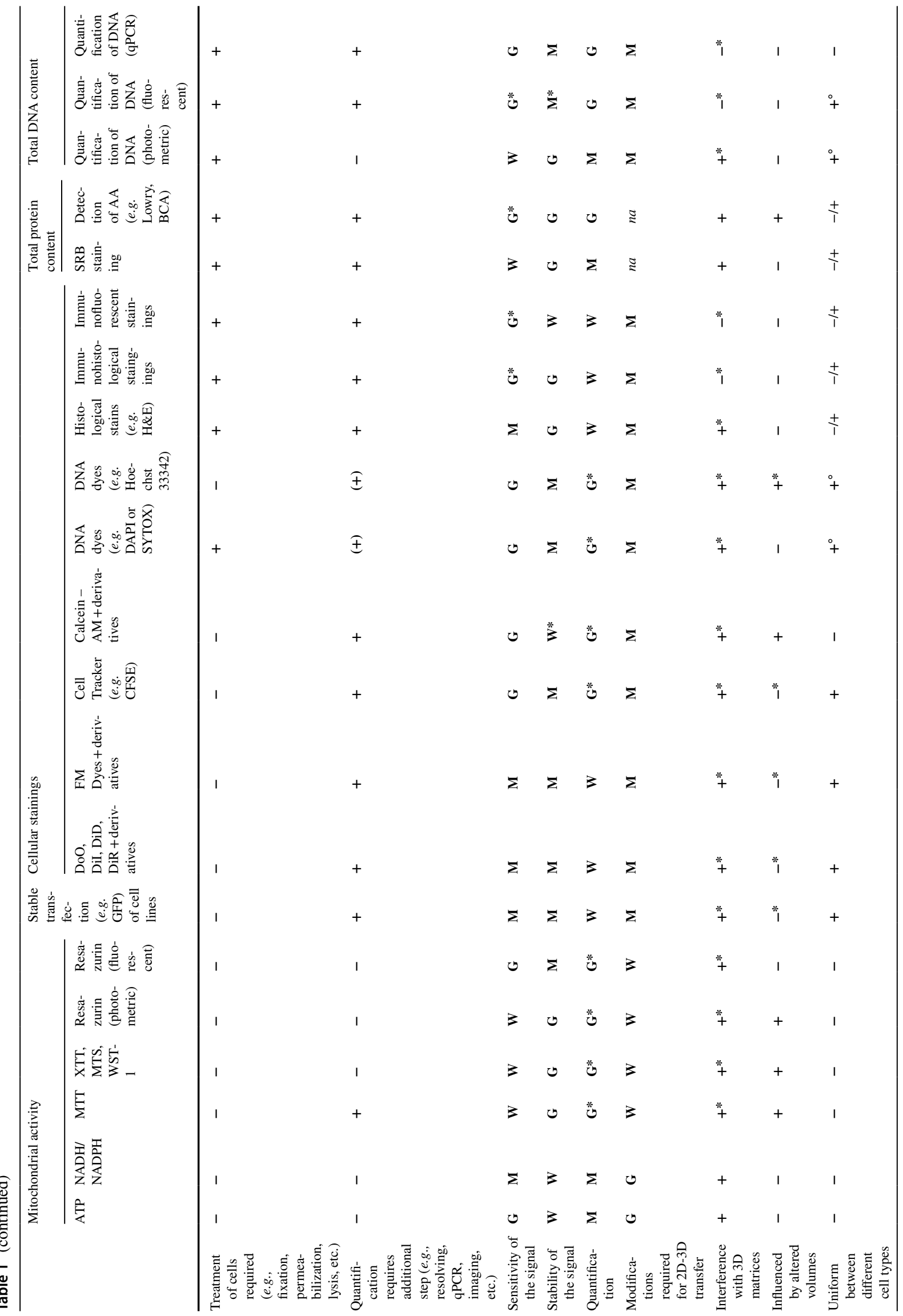




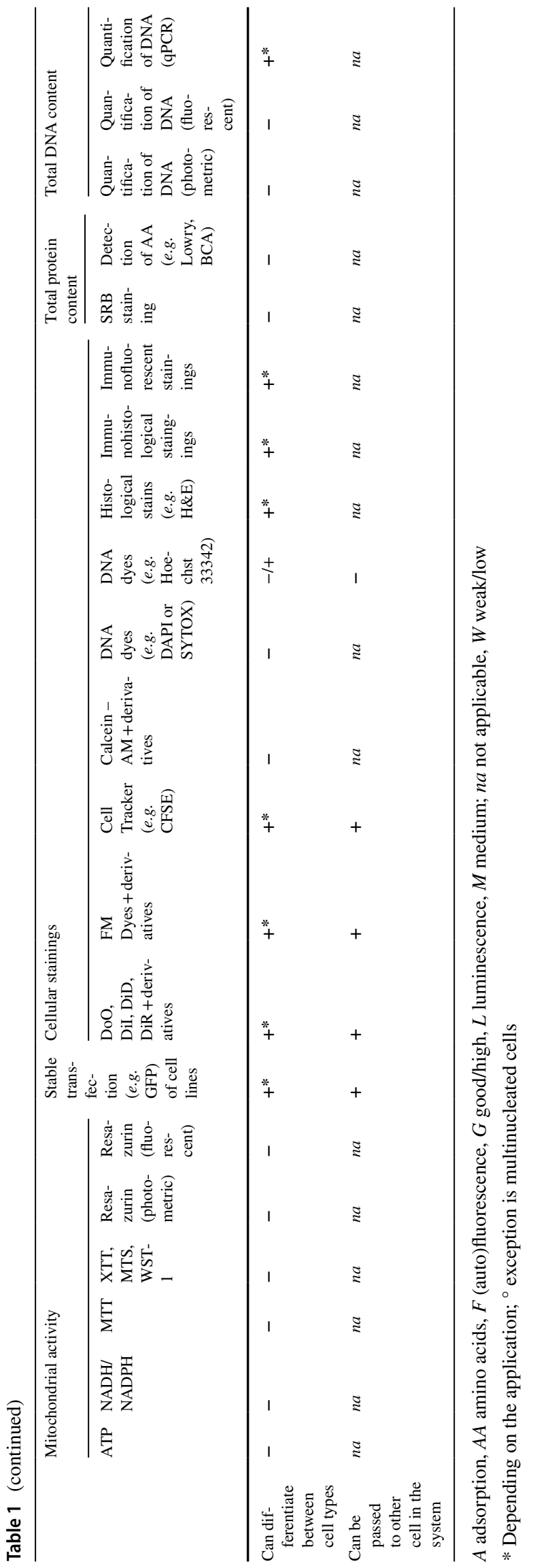

\section{Mitochondrial activity for normalization}

Most publications use the mitochondrial activity of cells for viability measures and normalization. There exist a considerable amount of assays to quickly and simply determine the bioenergetic status of intact cells (Brand and Nicholls 2011). Normalizing a system to the mitochondrial activity has the beauty that theoretically only viable cells are taken into consideration.

In cellular monolayers, often the bioenergetic intermediates ATP, NADH, or NADPH are determined. Though it is appealing to measure the amount of ATP in a cell using luminescence, the amount of cellular ATP does not safely report mitochondrial function as most of the adenine nucleotide in cells is present as ATP (Brand and Nicholls 2011). Therefore, many researchers determine the cellular NADH or NADPH. This is executed either by measuring autofluorescence or using colorimetric or fluorescent substrates which get reduced in an NADH- or NADPH-dependent manner (Henriques et al. 2011).

Examples for colorimetric assays are the classical MTT (3-(4,5-dimethylthiazol-2-yl)-2,5-diphenyl-2H-tetrazolium bromide) assay, or assays using water-soluble tetrazolium derivatives e.g. XTT (2,3-bis(2-methoxy-4-nitro5-sulfophenyl)-2H-tetrazolium-5-carboxanilide inner salt), MTS (3-(4,5-dimethyl-2-thiazolyl)-5-(3-carboxymethoxyphenyl)-2-(4-sulfophenyl)-2H-tetrazolium inner salt), or WST-1 (2-(4-iodophenyl)-3-(4-nitrophenyl)-5-(2,4disulfophenyl)-2H-tetrazolium monosodium salt). While MTT is reduced to insoluble formazan crystals, the secondgeneration tetrazolium salts XTT, MTS, and WST- 1 are reduced to hydrosoluble colored formazans in mitochondria of living cells, which ultimately reduces the toxicity of the assays and abolishes the need for an additional step of solubilization (Henriques et al. 2011). However, the watersoluble tetrazolium methods require an intermediate electron transfer reagent, mainly PMS (5-methyl-phenazinium methyl sulfate) or menadione, which represents the reduced agent in the assay transferring its electrons to the tetrazolium salts. Noteworthy, the production of colored aqueous formazan is amplified by the use of PMS in the assays, thereby increasing their detection limit (Henriques et al. 2011).

The non-toxic Resazurin conversion assay can be measured either photometric or fluorescent, which increases the sensitivity of the assay significantly. The water-soluble Resazurin (blue and non-fluorescent) is reduced to highly fluorescent Resorufin (pink) in mitochondria of intact cells. This reaction requires also NADH or NADPH as co-factor. Therefore, the amount of produced Resorufin is supposed to linearly increase with the amount of cellular NADH and NAPDH content available (Brand and Nicholls 2011).

Water-soluble assays have the advantage that the formed product is actively exported into the culture supernatant, 
which allows measurements in real time. One has to consider that the substrates and products may require time to perfuse in $3 \mathrm{D}$ cultures and may even react with the scaffold material. Furthermore, the scaffold material itself may limit the use of photometric assay-reaction solution must be transferred to separate plates or cuvettes for measurement, which still bears the risk that scaffold particles resolved in the reaction solution may interfere with the optical measurement. Measuring fluorescence, e.g., in the Resazurin conversion assay, is less susceptible for such interference.

The described assays may also be used to measure viability in ex vivo bone cultures. However, these methods have been originally developed for the conventional 2D mono-cultures. Using them in more complex 3D systems, e.g., co-cultures or ex vivo cultures, often requires adaption of the methodology. For that reason, there are certain limitations of the assays which the researchers have to be aware. 3D carriers or their solutes may interfere with the optical measurements, especially, when the assay is based on adsorption measurements. In case of fluorescent assays, possible autofluorescence of the $3 \mathrm{D}$ carrier material may disturb the measurement. In most cases, it is sufficient to simply transfer the reaction solution to a new microwell plate to eliminate the disturbances. When transferring the reaction solution is required, kinetic measures cannot be easily done any more. Even more challenging is the fact that the assays cannot differentiate between different cell types. Cell lines, even from the same lineage, do not have the same mitochondrial activity (Fig. 5a). This is not a limitation when mono-cultures are analyzed. In case of co-cultures, however, the increase in Resorufin conversion cannot be traced back to the different cell types. This is exemplarily shown in Fig. 5b, where the mitochondrial activity in the mono-cultures is in sum higher than the mitochondrial activity in the corresponding co-culture. It becomes even more complex, when cells are cultured on $3 \mathrm{D}$ carriers, as the mitochondrial activity of the same type of cell may change in response to stress such as slight variations in the $\mathrm{pH}$ or the stiffness of the carrier (Fig. 5c). In culture systems aiming to investigate bone function, where formation and degradation of matrix are a functional readout, this represents another limiting factor. From toxicological assays, it can be observed that cells under stress often show increase mitochondrial activity, prior to measurable damage by leakage of lactate dehydrogenase or reduction in total protein or DNA. Normalizing the mitochondrial activity to the total protein content may even be used as measure for cellular stress. Therefore, when using mitochondrial activity for normalization, it is advisable to use also alternative measures, e.g., total protein or DNA content, or glucose consumption (Haussling et al. 2019), although these measures also cannot easily distinguish between different cell types in a co-culture.

\section{Optical cell tracking for normalization}

Some studies also use different fluorescent labels to discriminate between different cell types in a co-culture. The available trackers and associated methods allow a great variety in the experimental setup. Most easily applied are the so-called cell trackers. Long-chain carbocyanines, e.g. $\mathrm{DiO}$ (3,3'-dioctadecyloxacarbocyanine perchlorate-green), DiI (1,1'-dioctadecyl-3,3,3',3'-tetramethylindocarbocyanine perchlorate-yellow), DiD (1,1'-dioctadecyl-3,3,3',3'tetra-methylindodicarbocyanine perchlorate-red), DiR (1,1'-dioctadecyl-3,3,3',3'-tetramethylindotricarbocyanine iodide-far red), or their derivatives, are weakly fluorescent

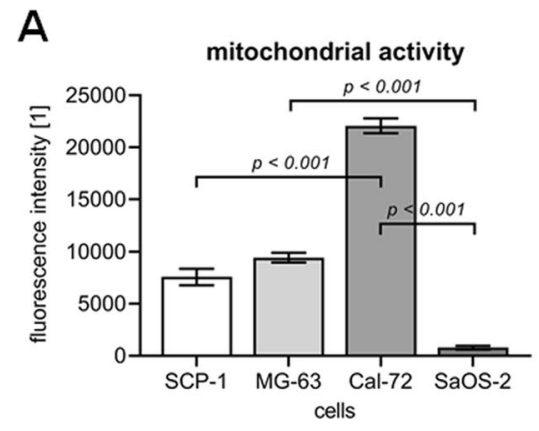

Fig. 5 Limitations of using mitochondrial activity for normalization. Mitochondrial activity was assessed by Resazurin conversion assay. a Mitochondrial activity varies between different osteogenic cell lines. Exemplary, $5 * 10^{4}$ cells of the SCP-1, MG-63, Cal-72, and SaOS-2 cell line were seeded, and after $24 \mathrm{~h}$, mitochondrial activity was determined. b Mitochondrial activity was measured in THP-1 and SaOS-2 cell cultures both in mono-culture and direct co-culture.
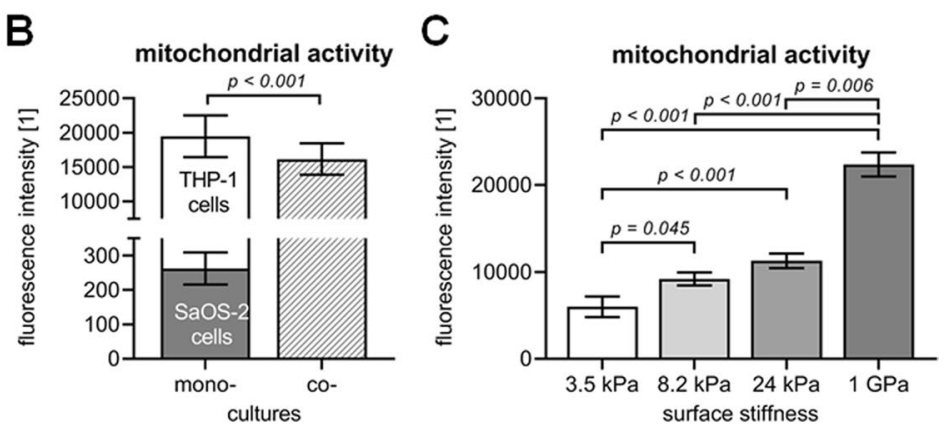

c Surface stiffness affects mitochondrial activity. $5 * 10^{4}$ cells of the same cell line were seeded on surfaces with different stiffness, and after $24 \mathrm{~h}$, mitochondrial activities were measured. Experiments were repeated three times $(\mathrm{N}=3)$ in triplicates $(n=3)$. Comparison of groups was performed by Kruskal-Wallis test followed Dunn's multiple comparison test 
in aqueous solution but highly fluorescent and even quite photostable when incorporated into cell membranes (Texier et al. 2009). These lipophilic dyes diffuse laterally within the plasma membrane of cells in culture medium or other aqueous buffers, resulting in staining of the entire cell. Such cell tracers have to be used with care-extensive washing of cells which is recommended to avoid the so-called microenvironmental contaminations, which occurs by passing on the dye from one cell to the neighboring cell (Lassailly et al. 2010). In co-cultures including osteoclast, this might not be sufficient, as osteoclasts are derived from activated myeloid cells, which possess phagocytic activity and thus may actively spread the tracers (Lassailly et al. 2010).

Comparably, lipophilic styryl dyes, also referred to as FM dyes, diffuse rapidly but also reversibly into plasma membranes of cells resulting in a strong fluorescent enhancement (Wu et al. 2009). FM dyes, e.g., FM1-43 (N-(3-triethylammonium-propyl)-4-(4-(dibutylamino)styryl)pyridinium dibromide-red), FM2-10 (N-(3-triethylammonium-propyl)4-(4-(diethyl-amino)styryl)pyridinium dibromide-orange), FM4-64 (N-(3-triethylammonium-propyl)-4-(6-(4-(diethylamino)phenyl)hexatrienyl)pyridinium dibromide-red), or FM5-95 (N-(3-trimethylammoniumpropyl)-4-(6-(4-(diethylamino)phenyl)hexatrienyl)pyridinium dibromide-red), are widely used to study endocytosis, vesicle trafficking, or organelle organization in living cells (Bolte et al. 2004). Nowadays, modified dyes which allow fixation of the stain (FX modifications) are available. Furthermore, fine chemical modifications of FM1-43, which is one of the most widely used FM probes, resulted in new probes, SP-468 (red) and SQ-535 (far red), which have enhanced photophysical properties, e.g., reduced crosstalk, higher brightness, or improved photostability (Collot et al. 2019). Similar to the long-chain carbocyanine dyes, it cannot be granted that dyes incorporated into the plasma membranes will not cause micro-environmental background by passing on the stain to neighboring cells or due to phagocytosis.

Live cell dyes work slightly different. The non- or low fluorescent dyes freely pass through plasma membranes into the cells, where they are transformed into cell membraneimpermeable fluorescent reaction products. The best-known representative of this group is calcein-AM (AM = acetoxymethyl) which is part of many live-dead staining kits. The non-fluorescent calcein-AM easily passes the plasma membrane, where it is converted to green-fluorescent calcein by intracellular esterases (Bratosin et al. 2005). The beauty to mark viable cells using fluorogenic compounds, e.g., calcein-AM and its derivatives (blue, orange, and red), has increased their frequency of use in cell and molecular biology. However, leakage of the fluorescent calcein or its interactions with exogenous stimulants, e.g., metal ions or electrochemically generated by-products, have been reported (Miles et al. 2015). Therefore, the use of adequate controls for accurate measurements and valid conclusions is inevitable. Considering live cell dyes for normalization, the same limitations than for measuring mitochondrial activity exist. The live cell dyes will not distinguish between the different cell types, and, therefore, need to be combined with other tracers.

Live cell dyes may be used to visualize living cells also in ex vivo cultures, being aware, that the dyes cannot differentiate between different cell types. In contrast to that, the described lipophilic dyes, which label the cell membranes, would not be of any use for the ex vivo models, unlike invasion of labelled cancer cells should be investigated in a metastasis assay. We have used yet another approach, by permanently labelling different cell types. For a co-culture of SaOS- 2 cells and THP-1 cells, we intended to stably transfect (using selection antibiotics) these cell lines with plasmids inducing over-expression of fluorophores. While green and red fluorescent SaOS-2 cell lines could be generated, the transfection efficiency of the myeloid THP-1 cells was not sufficient. Therefore, red fluorescent SaOS-2 cells were co-cultured with THP-1 cells. After exposure to calcein-AM, all living cells should appear green fluorescent, which allowed discrimination between the two cell types. However, some cells only showed the nuclear counterstain (Hoechst 33,342-blue-white arrows) questioning the efficiency of the method (Fig. 6a). Similar to all fluorescent tracers or markers, the method works very well in 2D cultures, but quickly reaches its limits in 3D cultures with non-transparent scaffolds (Fig. 2b) (Tendulkar et al. 2016). To make things worse, our transfected SaOS-2 cells showed altered mitochondrial and alkaline phosphatase (ALP) activity, which in turn affected the formation of mineralized matrix by these cells (Fig. 6c, d). This represent a limitation, one has to keep in mind, when using stably transformed cell lines. These examples show that there is, indeed, a large variety of fluorescent markers and tracers that can be used to track cells in co-cultures. When appropriate controls are done and automated image analysis is possible, these tools represent a very good option to trace and normalize cells in co-cultures, at least in 2D.

\section{Using DNA for normalization}

Another well-established technique to normalize cell cultures is the quantification of total protein or DNA, as this is supposed to be less affected by culture conditions than viability measures. As many cell carriers for 3D cultures contain some protein source, it is not advisable to use total protein content for normalization in 3D settings. It is less likely that cell carriers for 3D cultures contain DNA. Therefore, normalization using DNA may be feasible. Just recently, we 
A

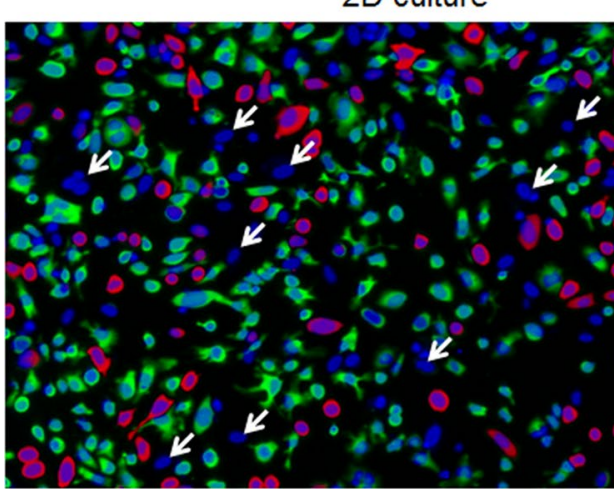

$B$

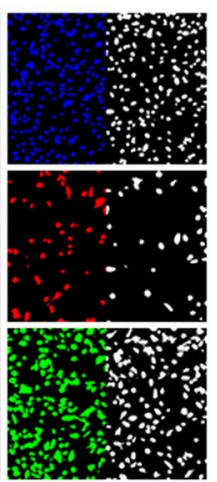

C

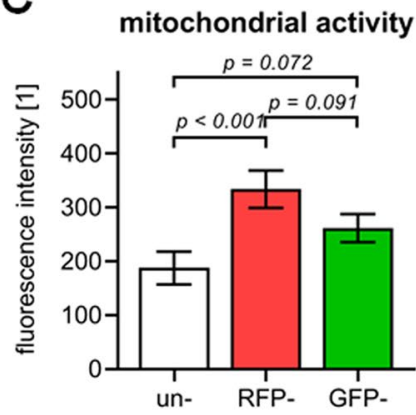

labeled SaOS-2 cells
D

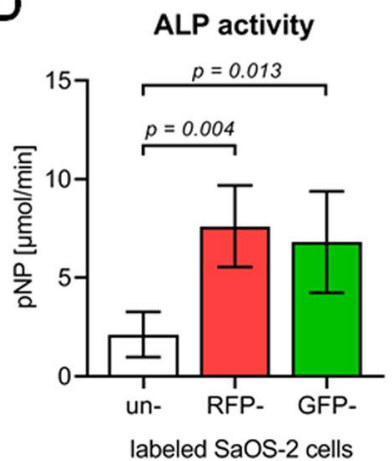

3D culture

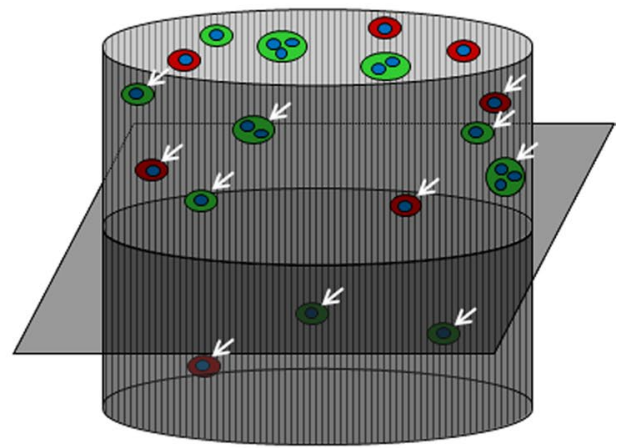

E

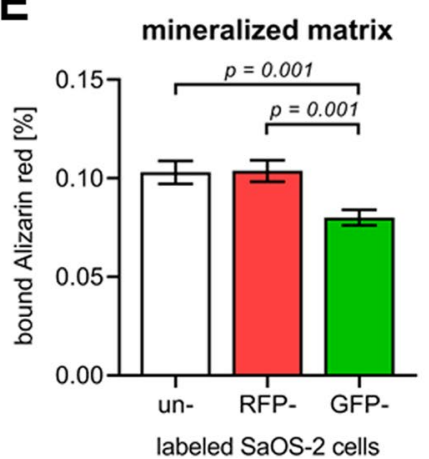

Fig. 6 Using fluorescent labels for normalization. SaOS-2 cell line was transfected to over-express a red fluorescent protein (RFP: Addgene plasmid \#54642 tdTomato-N1) or a green-fluorescent protein (GFP: Addgene plasmid \#54737 sfGFP_N1). a RFP-overexpressing SaOS- 2 cells (red) were directly co-cultured with THP-1 cells in a ratio of 1:2. After 4 days of conventional $2 \mathrm{D}$ culture viable cells were visualized with Calcein-AM (green). Nuclei were counterstained with Hoechst 33342 (blue). b Schematic overview on the respective

have described the DNA-based quantification of different cell types on scaffold-based 3D cultures (Ruoss et al. 2019).

Using this model, which is based on a co-culture of a murine cell line with a human cell line, we could compare different methods to retrieve DNA from cells seeded on the matrix, as well as the feasibility of different DNA quantification methods. Interestingly, the attempt to detach cells from the matrix prior to DNA isolation failed to isolate all DNA that was contained on the matrix. A simple $\mathrm{NaOH}$-based isolation technique (Ehnert et al. 2019b) is frequently used to isolate DNA from tissue samples for genotyping in mice effectively retrieved all DNA from the scaffolds. Comparing different DNA quantification methods showed that the limit of detection (LOD) and consequently limit of quantification (LOQ) were lowest for the fluorescent-based CyQuant assay, which also had the highest sensitivity (101-104\%). Surprisingly, neither the LOD and LOQ ( 1.5-fold higher) nor the sensitivity (95-98\%), was significantly higher for the conventional absorption-based quantification of DNA when
3D culture. c Mitochondrial activity of the un-/labelled SaOS-2 cells on day 4 of culture. d ALP activity of the un-/labelled SaOS-2 cells on day 4 of culture. e Mineralized matrix formed by the un-/labelled SaOS-2 cells after 10 days of culture. Experiments were repeated three times $(\mathrm{N}=3)$ in triplicates $(\mathrm{n}=3)$. Comparison of groups was performed by Kruskal-Wallis test followed by Dunn's multiple comparison test

compared with the CyQuant assay. The highest LOD and LOQ and the lowest sensitivity (88-98\%) had the fluorescent-based Hoechst 33342 assay. These three methods can only be used in mono-cultures or to assess the total amount of DNA in a co-culture. To distinguish between the different cell types in the co-culture a PCR using species-specific primers was performed. The PCR-based method showed an LOD, LOQ, and sensitivity (99\%) comparable to the quantification of DNA with the CyQuant assay and conventional absorption-based method, but could differentiate between the two cell types in the co-culture.

However, aiming for an all human co-culture model, we adapted the PCR-based detection method using sex-specific primers:

- UGT1A6 (uridine diphosphate glucuronosyl transferase 1A6), located on chromosome 2, was used to determine the total amount of DNA (Ruoss et al. 2019); 
A

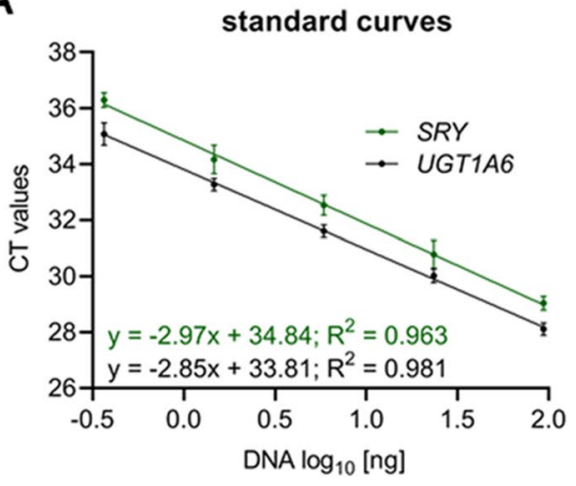

Fig. 7 Sex-specific qPCR-based DNA quantification for normalization. An in vitro fracture hematoma was generated as described by Pfeiffenberger et al. (Pfeiffenberger et al. 2019), using blood of a male donor and (female) SCP-1 cells. Normalization of the cells in culture was done by DNA content and sex-specific PCR. a Representative standard curves for the sex-specific PCRs. UGT1A6 located on chromosome 2 is representative for the total DNA amount. $S R Y$ located on

- $S R Y$ (sex-determining region Y), located on the Y-chromosome, was used to determine the amount of male DNA (Drobnič 2006);

- respective standard curves are given in Fig. 7a.

As model system to study early fracture healing an in vitro fracture hematoma was generated as described by Pfeiffenberger et al. (Pfeiffenberger et al. 2019). Briefly, the in vitro fracture hematomas were generated by mixing human whole blood of a male donor and $6 * 10^{4}$ cells of the immortalized (female) MSC SCP-1 cells. After mixing equal volumes of blood and cells $(120 \mu \mathrm{l})$ in the presence of calcium ions, in vitro hematomas formed, which remained stable over a culture period of at least 4 days. Whole DNA was isolated after hematoma dissolution and erythrocyte lysis using alkaline DNA extraction with $\mathrm{NaOH}$ (Ehnert et al. 2019b; Pfeiffenberger et al. 2019). Comparing the relative DNA amounts determined by UGT1A6 and SRY PCR showed that the relative amount of female DNA (SCP-1 cells) in the model system increased with the culture time.

Despite the possibility that the normalization to DNA content may reach limits, for example when dead cells are entrapped in a 3D environment, the proposed method represents a good alternative to the existing methods when cell-specific normalization of a co-culture system is required. Including a third human cell line may be challenging. A possibility might be the use of immortalized cell lines, e.g., the SCP-1 cell line or the HMEC-1 microvascular endothelial cell line, which offer the possibility to detect (PCR) sequences introduced into the genome

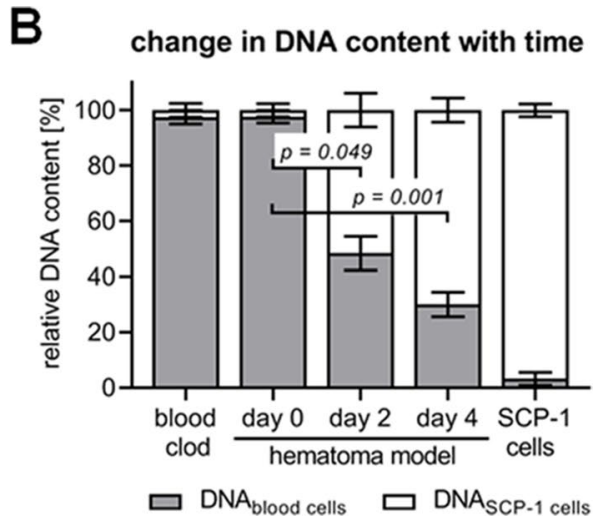

the Y-chromosome is representative for the amount of male DNA. b Change in relative DNA amounts in the in vitro fracture hematomas after 2 and 4 days of culture was determined by sex-specific PCR. Experiments were repeated three times $(\mathrm{N}=3)$ in duplicates $(n=2)$. Comparison of groups was performed by Kruskal-Wallis test followed Dunn's multiple comparison test

during immortalization (hTERT in SCP-1 cells or pSVT in HMEC-1 cells).

\section{Summary and conclusion}

In recent years, there have been great technical developments, when considering co-cultures of bone forming and resorbing cells. The combination of different cell types in 2D and 3D cultures, with and without mechanical stimuli, has been described many times. Advanced 3D carriers and dynamization of the model system allow investigating biocompatibility of implant materials or effect of drugs or their metabolites on bone metabolism. First attempts have been described to also include the interaction with endothelial cells (vascularization) and bone marrow adipocytes in these models, widening their application for investigating systemic bone diseases, e.g., diabetic osteopathy. When it comes to investigating fracture healing in vitro, the situation is even more complex and only first attempt to generate in vitro hematomas have been described. Comparing the huge technical progress with the advances in analytical methods to adequately characterize these models, the required modifications of the techniques from $2 \mathrm{D}$ to $3 \mathrm{D}$ and from mono-culture to co-culture still lack behind, lowering the full potential of the proposed model systems. Being aware of the strengths and limitations of the different in vitro or ex vivo model systems, they can be used in larger screening approaches, but will not be able to replace in vivo testing for verification. 
Table 2 Search strategy

\begin{tabular}{|c|c|c|c|}
\hline \multicolumn{2}{|c|}{ Search criteria } & \multirow{2}{*}{$\frac{\text { All }}{121}$} & \multirow{2}{*}{$\frac{\text { Reviews }}{2}$} \\
\hline$\# 1$ & “Osteoblast” AND “osteoclast" AND “co-culture" & & \\
\hline \#2 & "Bone” AND “endothelial” AND “co-culture” & 298 & 13 \\
\hline \#3 & "Ex vivo" AND "bone metabolism" AND “culture" & 19 & 1 \\
\hline \#4 & “Ex vivo" AND “bone metabolism” AND “model” & 11 & 0 \\
\hline \#5 & "Ex vivo" AND “bone growth” AND “culture" & 12 & 0 \\
\hline \#6 & "Ex vivo" AND "bone growth" AND "model" & 21 & 2 \\
\hline \#7 & "In vitro" AND “bone” AND “vascularized" & 254 & 14 \\
\hline \#8 & "Osteoblast" OR "osteoclast" AND "endothelial” AND "in vitro" & 297 & 13 \\
\hline \#9 & "Osteoblast" OR “osteoclast" AND “endothelial” AND “co-culture" & 50 & 2 \\
\hline$\# 10$ & \#1 OR \#2 OR \#3 OR \#4 OR \#5 OR \#6 OR \#7 OR \#8 OR \#9 & 981 & 43 \\
\hline
\end{tabular}

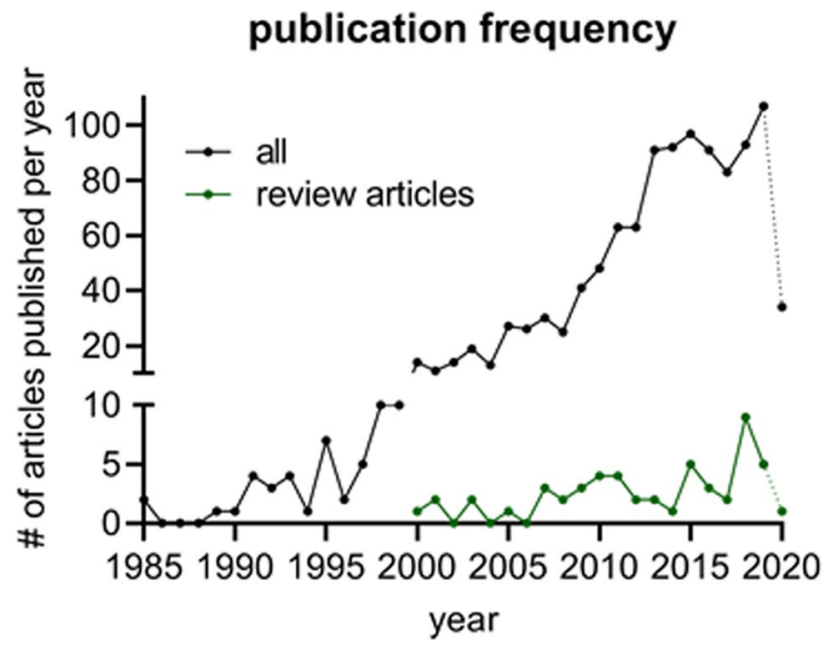

Fig. 8 Publication frequency with the above stated search terms (Table 1)

\section{Search criteria}

On the 5th of April 2020, a search was performed with PubMed and Web of Science, limited to manuscripts in English or German language. The search strategy is summarized in Table 2.

Considering only manuscripts in English or German languages, a total of 981 manuscripts remained for further screening, of which 43 were review articles. In Fig. 8, the number of papers published per year is presented.

Acknowledgements Plasmids for transfection, obtained via Addgene, were generated by Michael Davidson \& Nathan Shaner \& Roger Tsien $\&$ Geoffrey Waldo (Pedelacq et al. 2006; Shaner et al. 2004). Data presented in this review have been performed by R.H. and V.H. as part of their dissertation. We would like to thank Marina Häcker and Jasmin Lemke for excellent technical assistance.

Authors' contributions Conceptualization: $\mathrm{SE}$ and $\mathrm{AKN}$; methodology: SE, HR, and VH; investigation: HR RA-W, and VH; formal analysis: SE and HR; validation: RA-W; writing — original draft preparation: SE; writing - review and editing: all authors; visualization: SE; supervision: SE and AKN; funding acquisition: SE and AKN.
Funding Open Access funding enabled and organized by Projekt DEAL. This work was partially supported by the "Ministerium für Ländlichen Raum und Verbraucherschutz Baden-Württemberg" (14(34)-8402.43) and the Deutsche Forschungsgemeinschaft (EH471/2).

Availability of data and materials Review article with own data-these can be obtained from the corresponding author upon reasonable request.Code availability Not applicable.

\section{Compliances with ethical standards}

Conflicts of interest The authors declare that they have no known competing financial interests or personal relationships that could have appeared to influence the work reported in this paper.

Open Access This article is licensed under a Creative Commons Attribution 4.0 International License, which permits use, sharing, adaptation, distribution and reproduction in any medium or format, as long as you give appropriate credit to the original author(s) and the source, provide a link to the Creative Commons licence, and indicate if changes were made. The images or other third party material in this article are included in the article's Creative Commons licence, unless indicated otherwise in a credit line to the material. If material is not included in the article's Creative Commons licence and your intended use is not permitted by statutory regulation or exceeds the permitted use, you will need to obtain permission directly from the copyright holder. To view a copy of this licence, visit http://creativecommons.org/licenses/by/4.0/.

\section{References}

Abubakar AA, Noordin MM, Azmi TI, Kaka U, Loqman MY (2016) The use of rats and mice as animal models in ex vivo bone growth and development studies. Bone Joint Res 5(12):610-618. https://doi.org/10.1302/2046-3758.512.bjr-2016-0102.r2

Abubakar AA, Ibrahim SM, Ali AK et al (2019) Postnatal ex vivo rat model for longitudinal bone growth investigations. Anim Models Exp Med 2(1):34-43. https://doi.org/10.1002/ame2.12051

Adil M, Khan RA, Kalam A et al (2017) Effect of anti-diabetic drugs on bone metabolism: evidence from preclinical and clinical studies. 
Pharmacol Rep 69(6):1328-1340. https://doi.org/10.1016/j.phare p.2017.05.008

Aerssens J, Boonen S, Lowet G, Dequeker J (1998) Interspecies differences in bone composition, density, and quality: potential implications for in vivo bone research. Endocrinology 139(2):663670. https://doi.org/10.1210/endo.139.2.5751

Alfaqeeh SA, Tucker AS (2013) The slice culture method for following development of tooth germs in explant culture. J Visual Exp 81:e50824. https://doi.org/10.3791/50824

Arnaoutova I, Kleinman HK (2010) In vitro angiogenesis: endothelial cell tube formation on gelled basement membrane extract. Nat Protoc 5(4):628-635. https://doi.org/10.1038/nprot.2010.6

Ayobian-Markazi N, Fourootan T, Kharazifar MJ (2012) Comparison of cell viability and morphology of a human osteoblastlike cell line (SaOS-2) seeded on various bone substitute materials: an in vitro study. Dent Res J 9(1):86-92. https://doi. org/10.4103/1735-3327.92959

Barrach HJ, Neubert D (1980) Significance of organ culture techniques for evaluation of prenatal toxicity. Arch Toxicol 45(3):161-187. https://doi.org/10.1007/bf02418996

Batushansky A, Lopes EBP, Zhu S, Humphries KM, Griffin TM (2019) GC-MS method for metabolic profiling of mouse femoral head articular cartilage reveals distinct effects of tissue culture and development. Osteoarthr Cartil 27(9):1361-1371. https://doi. org/10.1016/j.joca.2019.05.010

Bellido T, Delgado-Calle J (2020) Ex vivo organ cultures as models to study bone biology. JBMR Plus. https://doi.org/10.1002/ jbm4.10345

Birbrair A, Frenette PS (2016) Niche heterogeneity in the bone marrow. Ann N Y Acad Sci 1370(1):82-96. https://doi.org/10.1111/ nyas. 13016

Blakytny R, Spraul M, Jude EB (2011) Review: the diabetic bone: a cellular and molecular perspective. Int J Low Extrem Wounds 10(1):16-32. https://doi.org/10.1177/1534734611400256

Bolte S, Talbot C, Boutte Y, Catrice O, Read ND, Satiat-Jeunemaitre B (2004) FM-dyes as experimental probes for dissecting vesicle trafficking in living plant cells. J Microsc 214(2):159-173. https ://doi.org/10.1111/j.0022-2720.2004.01348.x

Brand MD, Nicholls DG (2011) Assessing mitochondrial dysfunction in cells. Biochem J 435(2):297-312. https://doi.org/10.1042/ BJ20110162

Bratosin D, Mitrofan L, Palii C, Estaquier J, Montreuil J (2005) Novel fluorescence assay using calcein-AM for the determination of human erythrocyte viability and aging. Cytometry Part A 66(1):78-84. https://doi.org/10.1002/cyto.a.20152

Buckwalter JA, Glimcher MJ, Cooper RR, Recker R (1996) Bone biology. I: structure, blood supply, cells, matrix, and mineralization. Instr Course Lect 45:371-386

Bulnheim U, Müller P, Neumann HG et al (2014) Endothelial cells stimulate osteogenic differentiation of mesenchymal stem cells on calcium phosphate scaffolds. J Tissue Eng Regenerat Med 8(10):831-840. https://doi.org/10.1002/term.1590

Choudhary S, Ramasundaram P, Dziopa E et al (2018) Human ex vivo 3D bone model recapitulates osteocyte response to metastatic prostate cancer. Scientific Reports 8(1):17975. https://doi. org/10.1038/s41598-018-36424-x

Collot M, Boutant E, Fam KT, Danglot L, Klymchenko AS (2019) Molecular tuning of styryl dyes leads to versatile and efficient plasma membrane probes for cell and tissue imaging. bioRxiv. https://doi.org/10.1101/819383

Colombo JS, Howard-Jones RA, Young FI, Waddington RJ, Errington RJ, Sloan AJ (2015) A 3D ex vivo mandible slice system for longitudinal culturing of transplanted dental pulp progenitor cells. Cytometry Part A 87(10):921-928. https://doi.org/10.1002/ cyto.a. 22680
Curtin P, Youm H, Salih E (2012) Three-dimensional cancer-bone metastasis model using ex vivo co-cultures of live calvarial bones and cancer cells. Biomaterials 33(4):1065-1078. https:// doi.org/10.1016/j.biomaterials.2011.10.046

Daigneault M, Preston JA, Marriott HM, Whyte MK, Dockrell DH (2010) The identification of markers of macrophage differentiation in PMA-stimulated THP-1 cells and monocyte-derived macrophages. PLoS ONE 5(1):e8668. https://doi.org/10.1371/ journal.pone. 0008668

David V, Guignandon A, Martin A et al (2008) Ex Vivo bone formation in bovine trabecular bone cultured in a dynamic 3D bioreactor is enhanced by compressive mechanical strain. Tissue Eng Part A 14(1):117-126. https://doi.org/10.1089/ten.a.2007.0051

Davies CM, Jones DB, Stoddart MJ et al (2006) Mechanically loaded ex vivo bone culture system 'Zetos': systems and culture preparation. Eur Cell Mater 11:57-75. https://doi.org/10.22203/ecm. v011a07

Dawson JI, Oreffo RO (2008) Bridging the regeneration gap: stem cells, biomaterials and clinical translation in bone tissue engineering. Arch Biochem Biophys 473(2):124-131. https://doi. org/10.1016/j.abb.2008.03.024

Ding D, Xu H, Liang Q, Xu L, Zhao Y, Wang Y (2012) Over-expression of Sox 2 in C3H10T1/2 cells inhibits osteoblast differentiation through Wnt and MAPK signalling pathways. Int Orthop 36(5):1087-1094. https://doi.org/10.1007/s00264-011-1368-6

Drobnič K (2006) A new primer set in a SRY gene for sex identification. Int Congr Ser 1288:268-270. https://doi.org/10.1016/j. ics.2005.08.020

Ehnert S, Baur J, Schmitt A et al (2010) TGF- $\beta 1$ as possible link between loss of bone mineral density and chronic inflammation. PLoS ONE 5(11):e14073. https://doi.org/10.1371/journ al.pone. 0014073

Ehnert S, Häuser J, Kerler I et al (2011) Mesenchymale Stammzellen aus Fettgewebe-Die bessere Alternative zu Knochenmarkszellen für das Tissue Engineering von Knochen? Zeitschrift für Regenerative Medizin 1:3-8

Ehnert S, Freude T, Ihle C et al (2015) Factors circulating in the blood of type 2 diabetes mellitus patients affect osteoblast maturation-description of a novel in vitro model. Exp Cell Res 332(2):247-258. https://doi.org/10.1016/j.yexcr.2014.12.011

Ehnert S, Sreekumar V, Aspera-Werz RH et al (2017) TGF- $\beta 1$ impairs mechanosensation of human osteoblasts via HDAC6mediated shortening and distortion of primary cilia. J Mol Med 95:653-663 (in press)

Ehnert S, Aspera-Werz RH, Ihle C et al (2019a) Smoking dependent alterations in bone formation and inflammation represent major risk factors for complications following total joint arthroplasty. J Clin Med. https://doi.org/10.3390/jcm8030406

Ehnert S, Linnemann C, Braun B et al (2019b) One-Step ARMSPCR for the detection of SNPs-using the example of the PADI4 Gene. Methods Protoc. https://doi.org/10.3390/mps2030063

El-Ganainy AR, Elgeidi A (2010) Treatment of distal femoral fractures in elderly diabetic patients using minimally invasive percutaneous plating osteosynthesis (MIPPO). Acta Orthop Belg 76(4):503-506

Endres S, Kratz M, Wunsch S, Jones DB (2009) Zetos: a culture loading system for trabecular bone. Investigation of different loading signal intensities on bovine bone cylinders. J Musculoskeletal Neuro Interact 9(3):173-183

Engler AJ, Sen S, Sweeney HL, Discher DE (2006) Matrix elasticity directs stem cell lineage specification. Cell 126(4):677-689. https://doi.org/10.1016/j.cell.2006.06.044

Fabregat I, Caballero-Diaz D (2018) Transforming growth factor-beta-induced cell plasticity in liver fibrosis and 
hepatocarcinogenesis. Front Oncol 8:357. https://doi. org/10.3389/fonc.2018.00357

Florencio-Silva R, Sasso GR, Sasso-Cerri E, Simoes MJ, Cerri PS (2015) Biology of bone tissue: structure, function, and factors that influence bone cells. Biomed Res Int 2015:421746. https:// doi.org/10.1155/2015/421746

Forte L, Torricelli P, Boanini E et al (2016) Antioxidant and bone repair properties of quercetin-functionalized hydroxyapatite: an in vitro osteoblast-osteoclast-endothelial cell co-culture study. Acta Biomater 32:298-308. https://doi.org/10.1016/j.actbi o.2015.12.013

Freude T, Braun KF, Haug A et al (2012) Hyperinsulinemia reduces osteoblast activity in vitro via upregulation of TGF-beta. J Mol Med 90(11):1257-1266. https://doi.org/10.1007/s0010 9-012-0948-2

Frost HM (1994) Wolff's Law and bone's structural adaptations to mechanical usage: an overview for clinicians. Angle Orthod 64(3):175-188. https://doi.org/10.1043/00033219(1994)064\%3c0175:WLABSA\%3e2.0.CO;2

Fuchs S, Hofmann A, Kirkpatrick C (2007) Microvessel-like structures from outgrowth endothelial cells from human peripheral blood in 2-dimensional and 3-dimensional co-cultures with osteoblastic lineage cells. Tissue Eng 13(10):2577-2588. https://doi. org/10.1089/ten.2007.0022

Fuchs S, Ghanaati S, Orth C et al (2009) Contribution of outgrowth endothelial cells from human peripheral blood on in vivo vascularization of bone tissue engineered constructs based on starch polycaprolactone scaffolds. Biomaterials 30(4):526-534. https:// doi.org/10.1016/j.biomaterials.2008.09.058

Garrett IR (2003) Assessing bone formation using mouse calvarial organ cultures. Methods Mol Med 80:183-198. https://doi. org/10.1385/1-59259-366-6:183

George J, Kuboki Y, Miyata T (2006) Differentiation of mesenchymal stem cells into osteoblasts on honeycomb collagen scaffolds. Biotechnol Bioeng 95(3):404-411. https://doi.org/10.1002/bit.20939

Ghanaati S, Fuchs S, Webber MJ et al (2011) Rapid vascularization of starch-poly(caprolactone) in vivo by outgrowth endothelial cells in co-culture with primary osteoblasts. J Tissue Eng Regenerat Med 5(6):e136-e143. https://doi.org/10.1002/term.373

Gomes PS, Fernandes MH (2011) Rodent models in bone-related research: the relevance of calvarial defects in the assessment of bone regeneration strategies. Lab Anim 45(1):14-24. https://doi. org/10.1258/la.2010.010085

Green J, Schotland S, Stauber DJ, Kleeman CR, Clemens TL (1995) Cell-matrix interaction in bone: type I collagen modulates signal transduction in osteoblast-like cells. Am J Physiol 268(5 Pt 1):C1090-C1103. https://doi.org/10.1152/ajpce 11.1995.268.5.C1090

Greiner S, Kadow-Romacker A, Schmidmaier G, Wildemann B (2009) Cocultures of osteoblasts and osteoclasts are influenced by local application of zoledronic acid incorporated in a poly(D, L-lactide) implant coating. J Biomed Mater Res A 91(1):288-295. https://doi.org/10.1002/jbm.a.32245

Griffith LG, Swartz MA (2006) Capturing complex 3D tissue physiology in vitro. Nat Rev Mol Cell Biol 7(3):211-224. https://doi. org/10.1038/nrm1858

Hadida M, Marchat D (2020) Strategy for achieving standardized bone models. Biotechnol Bioeng 117(1):251-271. https://doi. org/10.1002/bit.27171

Haffner-Luntzer M, Hankenson KD, Ignatius A et al (2019) Review of animal models of comorbidities in fracture-healing research. J Orthopaedic Res 37(12):2491-2498. https://doi.org/10.1002/ jor. 24454

Hamann C, Kirschner S, Gunther KP, Hofbauer LC (2012) Bone, sweet bone-osteoporotic fractures in diabetes mellitus. Nat Rev Endocrinol 8(5):297-305. https://doi.org/10.1038/nrendo.2011.233
Harris JS, Bemenderfer TB, Wessel AR, Kacena MA (2013) A review of mouse critical size defect models in weight bearing bones. Bone 55(1):241-247. https://doi.org/10.1016/j.bone.2013.02.002

Haussling V, Deninger S, Vidoni L et al (2019) Impact of four protein additives in cryogels on osteogenic differentiation of adiposederived mesenchymal stem cells. Bioengineering. https://doi. org/10.3390/bioengineering6030067

Hegazy SK (2015) Evaluation of the anti-osteoporotic effects of metformin and sitagliptin in postmenopausal diabetic women. J Bone Miner Metab 33(2):207-212. https://doi.org/10.1007/ s00774-014-0581-y

Heinemann C, Heinemann S, Worch H, Hanke T (2011) Development of an osteoblast/osteoclast co-culture derived by human bone marrow stromal cells and human monocytes for biomaterials testing. Eur Cell Mater 21:80-93

Heinemann S, Heinemann C, Wenisch S, Alt V, Worch H, Hanke T (2013) Calcium phosphate phases integrated in silica/collagen nanocomposite xerogels enhance the bioactivity and ultimately manipulate the osteoblast/osteoclast ratio in a human co-culture model. Acta Biomater 9(1):4878-4888. https://doi.org/10.1016/j. actbio.2012.10.010

Henkel J, Woodruff MA, Epari DR et al (2013) Bone regeneration based on tissue engineering conceptions-a 21st Century perspective. Bone Res 1(3):216-248. https://doi.org/10.4248/BR201 303002

Henriques C, Moreira TLB, Maia-Brigagão C, Henriques-Pons A, Carvalho TMU, de Souza W (2011) Tetrazolium salt based methods for high-throughput evaluation of anti-parasite chemotherapy. Anal Methods 3(9):2148-2155. https://doi. org/10.1039/C1AY05219E

Hernandez RK, Do TP, Critchlow CW, Dent RE, Jick SS (2012) Patient-related risk factors for fracture-healing complications in the United Kingdom general practice research database. Acta Orthop 83(6):653-660. https://doi.org/10.3109/17453 674.2012.747054

Hidayat K, Du X, Shi BM (2019) Risk of fracture with dipeptidyl peptidase-4 inhibitors, glucagon-like peptide-1 receptor agonists, or sodium-glucose cotransporter- 2 inhibitors in realworld use: systematic review and meta-analysis of observational studies. Osteoporos Int 30(10):1923-1940. https://doi. org/10.1007/s00198-019-04968-x

Hofbauer LC, Brueck CC, Singh SK, Dobnig H (2007) Osteoporosis in patients with diabetes mellitus. J Bone Mineral Res 22(9):1317-1328. https://doi.org/10.1359/jbmr.070510

Hofbauer LC, Lecka-Czernik B, Seibel MJ (2016) Sweet and brittle-Diabetes mellitus and the skeleton. Bone 82:1. https://doi. org/10.1016/j.bone.2015.09.001

Hofmann A, Ritz U, Verrier S et al (2008) The effect of human osteoblasts on proliferation and neo-vessel formation of human umbilical vein endothelial cells in a long-term $3 \mathrm{D}$ co-culture on polyurethane scaffolds. Biomaterials 29(31):4217-4226. https://doi.org/10.1016/j.biomaterials.2008.07.024

Holstein JH, Garcia P, Histing T et al (2009) Advances in the establishment of defined mouse models for the study of fracture healing and bone regeneration. J Orthop Trauma 23(5 Suppl):S31-S38. https://doi.org/10.1097/BOT.0b013e3181 9f $27 \mathrm{e} 5$

Hopps E, Caimi G (2011) Exercise in obesity management. J Sports Med Phys Fitness 51(2):275-282

Horowitz MC, Berry R, Holtrup B et al (2017) Bone marrow adipocytes. Adipocyte 6(3):193-204. https://doi.org/10.1080/21623 945.2017.1367881

Houston DA, Staines KA, MacRae VE, Farquharson C (2016) Culture of murine embryonic metatarsals: a physiological model of endochondral ossification. J Visual Exp. https://doi. org/10.3791/54978 
Hwang YC, Jeong IK, Ahn KJ, Chung HY (2011) Circulating osteocalcin level is associated with improved glucose tolerance, insulin secretion and sensitivity independent of the plasma adiponectin level. Osteoporos Int. https://doi.org/10.1007/s00198-011-1679-x

Ihle C, Freude T, Bahrs C et al (2017) Malnutrition-an underestimated factor in the inpatient treatment of traumatology and orthopedic patients: a prospective evaluation of 1055 patients. Injury 48(3):628-636. https://doi.org/10.1016/j.injury.2017.01.036

Jablonski H, Rekasi H, Jager M (2016) The influence of calcitonin gene-related peptide on markers of bone metabolism in MG-63 osteoblast-like cells co-cultured with THP-1 macrophage-like cells under virtually osteolytic conditions. BMC Musculoskelet Disord 17:199. https://doi.org/10.1186/s12891-016-1044-5

Jain KG, Mohanty S, Ray AR, Malhotra R, Airan B (2015) Culture $\&$ differentiation of mesenchymal stem cell into osteoblast on degradable biomedical composite scaffold: in vitro study. Indian J Med Res 142(6):747-758. https://doi.org/10.4103/09715916.174568

James Kirkpatrick C, Fuchs S, Iris Hermanns M, Peters K, Unger RE (2007) Cell culture models of higher complexity in tissue engineering and regenerative medicine. Biomaterials 28(34):51935198. https://doi.org/10.1016/j.biomaterials.2007.08.012

Jansen ID, Vermeer JA, Bloemen V, Stap J, Everts V (2012) Osteoclast fusion and fission. Calcif Tissue Int 90(6):515-522. https://doi. org/10.1007/s00223-012-9600-y

Kalaitzoglou E, Fowlkes JL, Popescu I, Thrailkill KM (2019) Diabetes pharmacotherapy and effects on the musculoskeletal system. Diabetes Metab Res Rev 35(2):e3100. https://doi.org/10.1002/ dmrr.3100

Kawashima Y, Fritton JC, Yakar S et al (2009) Type 2 diabetic mice demonstrate slender long bones with increased fragility secondary to increased osteoclastogenesis. Bone 44(4):648-655. https ://doi.org/10.1016/j.bone.2008.12.012

Kheniser KG, Polanco Santos CM, Kashyap SR (2018) The effects of diabetes therapy on bone: a clinical perspective. J Diabetes Complicat 32(7):713-719. https://doi.org/10.1016/j.jdiac omp.2018.04.005

Kidder LS, Chen X, Schmidt AH, Lew WD (2009) Osteogenic protein-1 overcomes inhibition of fracture healing in the diabetic rat: a pilot study. Clin Orthop Relat Res 467(12):3249-3256. https:// doi.org/10.1007/s11999-008-0405-2

Kim YH, Jun JH, Woo KM, Ryoo HM, Kim GS, Baek JH (2006) Dexamethasone inhibits the formation of multinucleated osteoclasts via down-regulation of beta3 integrin expression. Arch Pharmacal Res 29(8):691-698. https://doi.org/10.1007/bf02968254

King AJ (2012) The use of animal models in diabetes research. Br J Pharmacol 166(3):877-894. https://doi.org/10.111 1/j.1476-5381.2012.01911.x

Kirkpatrick CJ, Fuchs S, Unger RE (2011) Co-culture systems for vascularization-learning from nature. Adv Drug Deliv Rev 63(45):291-299. https://doi.org/10.1016/j.addr.2011.01.009

Kline AJ, Gruen GS, Pape HC, Tarkin IS, Irrgang JJ, Wukich DK (2009) Early complications following the operative treatment of pilon fractures with and without diabetes. Foot Ankle Int 30(11):1042-1047. https://doi.org/10.3113/FAI.2009.1042

Kluter T, Hassan R, Rasch A et al (2020) An ex vivo bone defect model to evaluate bone substitutes and associated bone regeneration processes. Tissue Eng Part C Methods 26(1):56-65. https://doi. org/10.1089/ten.TEC.2019.0274

Knothe Tate ML, Knothe U (2000) An ex vivo model to study transport processes and fluid flow in loaded bone. J Biomech 33(2):247254. https://doi.org/10.1016/s0021-9290(99)00143-8

Kolar P, Schmidt-Bleek K, Schell H et al (2010) The early fracture hematoma and its potential role in fracture healing. Tissue Eng Part B Rev 16(4):427-434. https://doi.org/10.1089/ten. TEB.2009.0687
Kunimoto T, Okubo N, Minami Y et al (2016) A PTH-responsive circadian clock operates in ex vivo mouse femur fracture healing site. Scientific reports 6:22409. https://doi.org/10.1038/srep22409

La Fontaine J, Shibuya N, Sampson HW, Del Pilar Valderrama M (2011) Trabecular quality and cellular characteristics of normal, diabetic, and charcot bone. J Foot Ankle Surg. https://doi. org/10.1053/j.jfas.2011.05.005

Lapane KL, Jesdale BM, Dube CE, Pimentel CB, Rajpathak SN (2015) Sulfonylureas and risk of falls and fractures among nursing home residents with type 2 diabetes mellitus. Diabetes Res Clin Pract 109(2):411-419. https://doi.org/10.1016/j.diabres.2015.05.009

Lassailly F, Griessinger E, Bonnet D (2010) "Microenvironmental contaminations" induced by fluorescent lipophilic dyes used for noninvasive in vitro and in vivo cell tracking. Blood 115(26):53475354. https://doi.org/10.1182/blood-2009-05-224030

Lauvrak SU, Munthe E, Kresse SH et al (2013) Functional characterisation of osteosarcoma cell lines and identification of mRNAs and miRNAs associated with aggressive cancer phenotypes. Br J Cancer 109(8):2228-2236. https://doi.org/10.1038/bjc.2013.549

Lessmollmann U, Hinz N, Neubert D (1976) In vitro system for toxicological studies on the development of mammalian limb buds in a chemically defined medium. Arch Toxicol 36(2):169-176. https://doi.org/10.1007/bf00351978

Li M, Fuchs S, Bose T et al (2014) Mild heat stress enhances angiogenesis in a co-culture system consisting of primary human osteoblasts and outgrowth endothelial cells. Tissue Eng Part C Methods 20(4):328-339. https://doi.org/10.1089/ten.TEC.2013.0087

Lichtman MK, Otero-Vinas M, Falanga V (2016) Transforming growth factor beta (TGF-beta) isoforms in wound healing and fibrosis. Wound Repair Regenerat 24(2):215-222. https://doi.org/10.1111/ wrr. 12398

Lim S, Kim KM, Kim SG et al (2017) Effects of lobeglitazone, a novel thiazolidinedione, on bone mineral density in patients with type 2 diabetes mellitus over 52 weeks. Diabetes Metab J 41(5):377385. https://doi.org/10.4093/dmj.2017.41.5.377

Ma Y, Zhou Y, Wu F, Ji W, Zhang J, Wang X (2019) The bidirectional interactions between inflammation and coagulation in fracture hematoma. Tissue Eng Part B Rev 25(1):46-54. https://doi. org/10.1089/ten.TEB.2018.0157

Ma B, Li M, Fuchs S et al (2020) Short-term hypoxia promotes vascularization in co-culture system consisting of primary human osteoblasts and outgrowth endothelial cells. J Biomed Mater Res A 108(1):7-18. https://doi.org/10.1002/jbm.a.36786

Madsen SH, Goettrup AS, Thomsen G et al (2011) Characterization of an ex vivo femoral head model assessed by markers of bone and cartilage turnover. Cartilage 2(3):265-278. https://doi. org/10.1177/1947603510383855

Marcellini S, Henriquez JP, Bertin A (2012) Control of osteogenesis by the canonical Wnt and BMP pathways in vivo: cooperation and antagonism between the canonical Wnt and BMP pathways as cells differentiate from osteochondroprogenitors to osteoblasts and osteocytes. BioEssays 34(11):953-962. https://doi. org/10.1002/bies.201200061

Marino S, Staines KA, Brown G, Howard-Jones RA, Adamczyk M (2016) Models of ex vivo explant cultures: applications in bone research. BoneKEy Rep 5:818. https://doi.org/10.1038/bonek ey.2016.49

Marino S, Bishop RT, Carrasco G, Logan JG, Li B, Idris AI (2019) Pharmacological inhibition of $\mathrm{NF \kappa B}$ reduces prostate cancer related osteoclastogenesis in vitro and osteolysis ex vivo. Calcif Tissue Int 105(2):193-204. https://doi.org/10.1007/s00223-01900538-9

Mayr-Wohlfart U, Fiedler J, Gunther KP, Puhl W, Kessler S (2001) Proliferation and differentiation rates of a human osteoblast-like cell line (SaOS-2) in contact with different bone substitute materials. J Biomed Mater Res 57(1):132-139 
Mazziotti G, Gola M, Bianchi A et al (2011) Influence of diabetes mellitus on vertebral fractures in men with acromegaly. Endocrine. https://doi.org/10.1007/s12020-011-9486-x

Mehta SK, Breitbart EA, Berberian WS, Liporace FA, Lin SS (2010) Bone and wound healing in the diabetic patient. Foot Ankle Clin 15(3):411-437. https://doi.org/10.1016/j.fcl.2010.03.005

Melin M, Joffre-Romeas A, Farges JC, Couble ML, Magloire H, Bleicher F (2000) Effects of TGFbeta1 on dental pulp cells in cultured human tooth slices. J Dent Res 79(9):1689-1696. https ://doi.org/10.1177/00220345000790090901

Meng XM, Nikolic-Paterson DJ, Lan HY (2016) TGF-beta: the master regulator of fibrosis. Nat Rev Nephrol 12(6):325-338. https://doi. org/10.1038/nrneph.2016.48

Miles FL, Lynch JE, Sikes RA (2015) Cell-based assays using calcein acetoxymethyl ester show variation in fluorescence with treatment conditions. J Biol Methods. https://doi.org/10.14440 /jbm.2015.73

Mohammad KS, Chirgwin JM, Guise TA (2008) Assessing new bone formation in neonatal calvarial organ cultures. Methods Mol Bio 455:37-50. https://doi.org/10.1007/978-1-59745-104-8_3

Mori H, Okada Y, Tanaka Y (2017) The Effects of Pioglitazone on bone formation and resorption markers in type 2 diabetes mellitus. Intern Med 56(11):1301-1306. https://doi.org/10.2169/inter nalmedicine.56.8096

Morrison SJ, Scadden DT (2014) The bone marrow niche for haematopoietic stem cells. Nature 505(7483):327-334. https://doi. org/10.1038/nature 12984

Murphy CM, O'Brien FJ (2010) Understanding the effect of mean pore size on cell activity in collagen-glycosaminoglycan scaffolds. Cell Adh Migr 4(3):377-381. https://doi.org/10.4161/ cam.4.3.11747

Muzic V, Katusic Bojanac A, Juric-Lekic G et al (2013) Epigenetic drug 5-azacytidine impairs proliferation of rat limb buds in an organotypic model-system in vitro. Croat Med J 54(5):489495. https://doi.org/10.3325/cmj.2013.54.489

Nuche-Berenguer B, Moreno P, Esbrit P et al (2009) Effect of GLP-1 treatment on bone turnover in normal, type 2 diabetic, and insulin-resistant states. Calcif Tissue Int 84(6):453-461. https ://doi.org/10.1007/s00223-009-9220-3

Okubo N, Minami Y, Fujiwara H et al (2013) Prolonged bioluminescence monitoring in mouse ex vivo bone culture revealed persistent circadian rhythms in articular cartilages and growth plates. PLoS ONE 8(11):e78306. https://doi.org/10.1371/journ al.pone.0078306

Okubo N, Fujiwara H, Minami Y et al (2015) Parathyroid hormone resets the cartilage circadian clock of the organ-cultured murine femur. Acta Orthop 86(5):627-631. https://doi. org/10.3109/17453674.2015.1029393

Owen R, Reilly GC (2018) In vitro models of bone remodelling and associated disorders. Front Bioeng Biotechnol 6:134. https:// doi.org/10.3389/fbioe.2018.00134

Padilla PI, Wada A, Yahiro K et al (2000) Morphologic differentiation of HL-60 cells is associated with appearance of RPTPbeta and induction of Helicobacter pylori VacA sensitivity. J Bio Chem 275(20):15200-15206. https://doi.org/10.1074/ jbc.275.20.15200

Papadimitropoulos A, Scherberich A, Guven S et al (2011) A 3D in vitro bone organ model using human progenitor cells. Eur Cell Mater 21:445-458 discussion 458

Paradis FH, Yan H, Huang C, Hales BF (2019) The murine limb bud in culture as an in vitro teratogenicity test system. Methods Mol Biol 1965:73-91. https://doi. org/10.1007/978-1-4939-9182-2_6

Parivar K, Kouchesfehani MH, Boojar MM, Hayati RN (2006) Organ culture studies on the development of mouse embryo limb buds under EMF influence. Int J Radiat Biol 82(7):455-464. https:// doi.org/10.1080/09553000600863056

Park SB, Seo KW, So AY et al (2012) SOX2 has a crucial role in the lineage determination and proliferation of mesenchymal stem cells through Dickkopf-1 and c-MYC. Cell Death Differ 19(3):534-545. https://doi.org/10.1038/cdd.2011.137

Pedelacq JD, Cabantous S, Tran T, Terwilliger TC, Waldo GS (2006) Engineering and characterization of a superfolder green fluorescent protein. Nat Biotechnol 24(1):79-88. https://doi. org/10.1038/nbt1172

Penolazzi L, Lolli A, Sardelli L et al (2016) Establishment of a 3D-dynamic osteoblasts-osteoclasts co-culture model to simulate the jawbone microenvironment in vitro. Life Sci 152:82-93. https://doi.org/10.1016/j.lfs.2016.03.035

Pfeiffenberger M, Bartsch J, Hoff P et al (2019) Hypoxia and mesenchymal stromal cells as key drivers of initial fracture healing in an equine in vitro fracture hematoma model. PLoS ONE 14(4):e0214276. https://doi.org/10.1371/journal.pone.0214276

Pinho S, Frenette PS (2019) Haematopoietic stem cell activity and interactions with the niche. Nat Rev Mol Cell Biol 20(5):303320. https://doi.org/10.1038/s41580-019-0103-9

Proffit WR, Ackerman JL (1964) Fluoride: its effects on 2 parameters of bone growth in organ culture. Science 145(3635):932-934. https://doi.org/10.1126/science.145.3635.932

Pscherer S, Freude T, Forst T, Nussler AK, Braun KF, Ehnert S (2013) Anti-diabetic treatment regulates pro-fibrotic TGF- $\beta$ serum levels in type 2 diabetics. Diabetol Metab Syndr 5(1):48. https://doi. org/10.1186/1758-5996-5-48

Pscherer S, Sandmann GH, Ehnert S, Nussler AK, Stockle U, Freude T (2015) Delayed fracture healing in diabetics with distal radius fractures. Acta Chir Orthop Traumatol Cech 82(4):268-273

Pscherer S, Kostev K, Dippel FW, Rathmann W (2016a) Fracture risk in patients with type 2 diabetes under different antidiabetic treatment regimens: a retrospective database analysis in primary care. Diabetes Metab Syndr Obes 9:17-23. https://doi.org/10.2147/ DMSO.S101370

Pscherer S, Nussler A, Bahrs C et al (2016b) Retrospective analysis of diabetics with regard to treatment duration and costs. Z Orthop Unfall. https://doi.org/10.1055/s-0042-116328

Rajpathak SN, Fu C, Brodovicz KG, Engel SS, Lapane K (2015) Sulfonylurea use and risk of hip fractures among elderly men and women with type 2 diabetes. Drugs Aging 32(4):321-327. https ://doi.org/10.1007/s40266-015-0254-0

Rawlinson SC, el-Haj AJ, Minter SL, Tavares IA, Bennett A, Lanyon LE (1991) Loading-related increases in prostaglandin production in cores of adult canine cancellous bone in vitro: a role for prostacyclin in adaptive bone remodeling? J Bone Mineral Res 6(12):1345-1351. https://doi.org/10.1002/jbmr.5650061212

Rees DA, Alcolado JC (2005) Animal models of diabetes mellitus. Diabet Med 22(4):359-370. https://doi.org/10.111 1/j.1464-5491.2005.01499.x

Rendina-Ruedy E, Graef JL, Davis MR et al (2016) Strain differences in the attenuation of bone accrual in a young growing mouse model of insulin resistance. J Bone Miner Metab 34(4):380-394. https://doi.org/10.1007/s00774-015-0685-z

Retzepi M, Donos N (2010) The effect of diabetes mellitus on osseous healing. Clin Oral Implants Res 21(7):673-681. https://doi.org/ 10.1111/j.1600-0501.2010.01923.x

Robinson AH, Pasapula C, Brodsky JW (2009) Surgical aspects of the diabetic foot. J Bone Joint Surg Br 91(1):1-7. https://doi. org/10.1302/0301-620X.91B1.21196

Rochet N, Leroy P, Far DF, Ollier L, Loubat A, Rossi B (2003) CAL72: a human osteosarcoma cell line with unique effects on hematopoietic cells. Eur J Haematol 70(1):43-52. https://doi.org/10.1 034/j.1600-0609.2003.02766.x 
Rosen CJ, Bouxsein ML (2006) Mechanisms of disease: is osteoporosis the obesity of bone? Nat Clin Pract Rheumatol 2(1):35-43. https ://doi.org/10.1038/ncprheum0070

Ruoss M, Kieber V, Rebholz S et al (2019) Cell-type-specific quantification of a scaffold-based 3D liver co-culture. Methods Protoc. https://doi.org/10.3390/mps3010001

Salamanna F, Borsari V, Brogini S et al (2016) An in vitro 3D bone metastasis model by using a human bone tissue culture and human sex-related cancer cells. Oncotarget 7(47):76966-76983. https://doi.org/10.18632/oncotarget.12763

Salih E (2019) Ex-vivo model systems of cancer-bone cell interactions. Methods Mol Biol 1914:217-240. https://doi. org/10.1007/978-1-4939-8997-3_11

Sathi GA, Kenmizaki K, Yamaguchi S et al (2015) Early initiation of endochondral ossification of mouse femur cultured in hydrogel with different mechanical stiffness. Tissue Eng Part C Methods 21(6):567-575. https://doi.org/10.1089/ten.TEC.2014.0475

Schlundt C, Bucher CH, Tsitsilonis S, Schell H, Duda GN, SchmidtBleek K (2018) Clinical and research approaches to treat nonunion fracture. Curr Osteoporos Rep 16(2):155-168. https://doi. org/10.1007/s11914-018-0432-1

Seo E, Basu-Roy U, Gunaratne PH et al (2013) SOX2 Regulates YAP1 to maintain stemness and determine cell fate in the osteo-adipo lineage. Cell Reports 3(6):2075-2087. https://doi.org/10.1016/j. celrep.2013.05.029

Shaner NC, Campbell RE, Steinbach PA, Giepmans BN, Palmer AE, Tsien RY (2004) Improved monomeric red, orange and yellow fluorescent proteins derived from Discosoma sp. red fluorescent protein. Nat Biotechnol 22(12):1567-1572. https://doi. org/10.1038/nbt1037

Sheu A, Diamond T (2016) Secondary osteoporosis. Aust Prescr 39(3):85-87. https://doi.org/10.18773/austprescr.2016.038

Shi Y, Wang F, Tiwari S et al (2016) Role of myeloid early endothelial progenitor cells in bone formation and osteoclast differentiation in tissue construct based on hydroxyapatite poly(ester-urethane) scaffolds. J Orthopaedic Res 34(11):1922-1932. https://doi. org/10.1002/jor.23222

Simpson AH, Murray IR (2015) Osteoporotic fracture models. Curr Osteoporos Rep 13(1):9-15. https://doi.org/10.1007/s1191 4-014-0246-8

Simpson AE, Stoddart MJ, Davies CM et al (2009) TGFbeta3 and loading increases osteocyte survival in human cancellous bone cultured ex vivo. Cell Biochem Funct 27(1):23-29. https://doi. org/10.1002/cbf. 1529

Sloan AJ, Taylor SY, Smith EL et al (2013) A novel ex vivo culture model for inflammatory bone destruction. J Dent Res 92(8):728734. https://doi.org/10.1177/0022034513495240

Smith EL, Locke M, Waddington RJ, Sloan AJ (2010) An ex vivo rodent mandible culture model for bone repair. Tissue Eng Part C, Methods 16(6):1287-1296. https://doi.org/10.1089/ten. TEC.2009.0698

Smith EL, Kanczler JM, Oreffo RO (2013) A new take on an old story: chick limb organ culture for skeletal niche development and regenerative medicine evaluation. Eur Cell Mater 26:91-106. https://doi.org/10.22203/ecm.v026a07

Smith EL, Rashidi H, Kanczler JM, Shakesheff KM, Oreffo RO (2015) The effects of $1 \alpha, 25$-dihydroxyvitamin D3 and transforming growth factor- $\beta 3$ on bone development in an ex vivo organotypic culture system of embryonic chick femora. PLoS ONE 10(4):e0121653. https://doi.org/10.1371/journal.pone.0121653

Soroceanu MA, Miao D, Bai XY, Su H, Goltzman D, Karaplis AC (2004) Rosiglitazone impacts negatively on bone by promoting osteoblast/osteocyte apoptosis. J Endocrinol 183(1):203-216. https://doi.org/10.1677/joe.1.05723

Srinivasaiah S, Musumeci G, Mohan T et al (2019) A $300 \mu \mathrm{m}$ organotypic bone slice culture model for temporal investigation of endochondral osteogenesis. Tissue Eng Part C, Methods 25(4):197-212. https://doi.org/10.1089/ten.TEC.2018.0368

Stoddart MJ, Furlong PI, Simpson A, Davies CM, Richards RG (2006) A comparison of non-radioactive methods for assessing viability in ex vivo cultured cancellous bone: technical note. Eur Cell Mater 12:16-25. https://doi.org/10.22203/ecm.v012a02

Sun W, Motta A, Shi Y et al (2016) Co-culture of outgrowth endothelial cells with human mesenchymal stem cells in silk fibroin hydrogels promotes angiogenesis. Biomed Mater 11(3):035009. https://doi.org/10.1088/1748-6041/11/3/035009

Sun M, Chi G, Xu J et al (2018) Extracellular matrix stiffness controls osteogenic differentiation of mesenchymal stem cells mediated by integrin alpha5. Stem Cell Res Therapy 9(1):52. https://doi. org/10.1186/s13287-018-0798-0

Tecles O, Laurent P, Aubut V, About I (2008) Human tooth culture: a study model for reparative dentinogenesis and direct pulp capping materials biocompatibility. J Biomed Mater Res B Appl Biomater 85(1):180-187. https://doi.org/10.1002/jbm.b.30933

Templeton ZS, Bachmann MH, Alluri RV, Maloney WJ, Contag CH, King BL (2015) Methods for culturing human femur tissue explants to study breast cancer cell colonization of the metastatic niche. J Visual Exp. https://doi.org/10.3791/52656

Tendulkar G, Grau P, Ziegler P et al (2016) Imaging cell viability on non-transparent scaffolds-using the example of a novel knitted titanium implant. J Visual Exp. https://doi.org/10.3791/54537

Texier I, Goutayer M, Da Silva A et al (2009) Cyanine-loaded lipid nanoparticles for improved in vivo fluorescence imaging. J Biomed Optics 14(5):054005. https://doi.org/10.1117/1.3213606

Thein-Han WW, Misra RD (2009) Biomimetic chitosan-nanohydroxyapatite composite scaffolds for bone tissue engineering. Acta Biomater 5(4):1182-1197. https://doi.org/10.1016/j.actbi o.2008.11.025

Tortelli F, Pujic N, Liu Y, Laroche N, Vico L, Cancedda R (2009) Osteoblast and osteoclast differentiation in an in vitro threedimensional model of bone. Tissue Eng Part A 15(9):2373-2383. https://doi.org/10.1089/ten.tea.2008.0501

Trojani C, Weiss P, Michiels JF et al (2005) Three-dimensional culture and differentiation of human osteogenic cells in an injectable hydroxypropylmethylcellulose hydrogel. Biomaterials 26(27):5509-5517. https://doi.org/10.1016/j.biomateria ls.2005.02.001

Uribe V, Rosello-Diez A (2019) Culturing and measuring fetal and newborn murine long bones. J Visual Exp. https://doi. org/10.3791/59509

Vajgel A, Mardas N, Farias BC, Petrie A, Cimoes R, Donos N (2014) A systematic review on the critical size defect model. Clin Oral Implants Res 25(8):879-893. https://doi.org/10.1111/clr.12194

Villafan-Bernal JR, Sanchez-Enriquez S, Munoz-Valle JF (2011) Molecular modulation of osteocalcin and its relevance in diabetes (Review). Int J Mol Med. https://doi.org/10.3892/ijmm.2011.706

Vivanco J, Garcia S, Ploeg HL, Alvarez G, Cullen D, Smith EL (2013) Apparent elastic modulus of ex vivo trabecular bovine bone increases with dynamic loading. Proc Inst Mech Eng [H] 227(8):904-912. https://doi.org/10.1177/0954411913486855

Warabi S, Tachibana Y, Kumegawa M, Hakeda Y (2001) Dexamethasone inhibits bone resorption by indirectly inducing apoptosis of the bone-resorbing osteoclasts via the action of osteoblastic cells. Cytotechnology 35(1):25-34. https://doi.org/10.1023/A:10081 59332152

Watts NB, Bilezikian JP, Usiskin K et al (2016) Effects of canagliflozin on fracture risk in patients with type 2 diabetes mellitus. J Clin Endocrinol Metab 101(1):157-166. https://doi.org/10.1210/ jc. 2015-3167

Weng W, Haussling V, Aspera-Werz RH et al (2020) Material-Dependent formation and degradation of bone matrix-comparison of 
two cryogels. Bioengineering. https://doi.org/10.3390/bioenginee ring7020052

Wintermeyer E, Ihle C, Ehnert S et al (2018) Assessment of the influence of diabetes mellitus and malnutrition on the postoperative complication rate and quality of life of patients in a clinic focused on trauma surgery. Z Orthop Unfall. https://doi. org/10.1055/a-0654-5504

Won HY, Lee JA, Park ZS et al (2011) Prominent bone loss mediated by RANKL and IL-17 produced by CD $4+\mathrm{T}$ cells in TallyHo/ JngJ mice. PLoS ONE 6(3):e18168. https://doi.org/10.1371/journ al.pone. 0018168

Wu Y, Yeh FL, Mao F, Chapman ER (2009) Biophysical characterization of styryl dye-membrane interactions. Biophys J 97(1):101109. https://doi.org/10.1016/j.bpj.2009.04.028

Wu L, Feyerabend F, Schilling AF, Willumeit-Romer R, Luthringer BJ (2015) Effects of extracellular magnesium extract on the proliferation and differentiation of human osteoblasts and osteoclasts in coculture. Acta Biomater 27:294-304. https://doi.org/10.1016/j. actbio.2015.08.042

Wukich DK, Joseph A, Ryan M, Ramirez C, Irrgang JJ (2011) Outcomes of ankle fractures in patients with uncomplicated versus complicated diabetes. Foot Ankle Int 32(2):120-130. https://doi. org/10.3113/FAI.2011.0120

Yang J, Huang C, Wu S et al (2017) The effects of dipeptidyl peptidase- 4 inhibitors on bone fracture among patients with type 2 diabetes mellitus: a network meta-analysis of randomized controlled trials. PLoS ONE 12(12):e0187537. https://doi. org/10.1371/journal.pone.0187537
Yue Y, Meng K, Pu Y, Zhang X (2017) Transforming growth factor beta (TGF-beta) mediates cardiac fibrosis and induces diabetic cardiomyopathy. Diabetes Res Clin Pract 133:124-130. https:// doi.org/10.1016/j.diabres.2017.08.018

Zachos C, Steubesand N, Seekamp A, Fuchs S, Lippross S (2014) Cocultures of programmable cells of monocytic origin and mesenchymal stem cells do increase osteogenic differentiation. J Orthopaedic Res 32(10):1264-1270. https://doi.org/10.1002/jor.22663

Zehnder T, Boccaccini A, Detsch R (2017) Biofabrication of a coculture system in an osteoid-like hydrogel matrix. Biofabrication. https://doi.org/10.1088/1758-5090/aa64ec

Zhang K, Fan Y, Dunne N, Li X (2018) Effect of microporosity on scaffolds for bone tissue engineering. Regen Biomater 5(2):115-124. https://doi.org/10.1093/rb/rby001

Zhao W, Li X, Liu X, Zhang N, Wen X (2014) Effects of substrate stiffness on adipogenic and osteogenic differentiation of human mesenchymal stem cells. Mat Sci Eng CMat Biol Appl 40:316-323. https://doi.org/10.1016/j.msec.2014.03.048

Zhu S, Ehnert S, Rouss M et al (2018) From the clinical problem to the basic research-co-culture models of osteoblasts and osteoclasts. Int J Mol Sci. https://doi.org/10.3390/ijms19082284

Publisher's Note Springer Nature remains neutral with regard to jurisdictional claims in published maps and institutional affiliations. 